\title{
Engineering management for high-end equipment intelligent manufacturing
}

C) The Author(s) 2018. Published by Higher Education Press. This is an open access article under the CC BY license (http:// creativecommons.org/licenses/by/4.0)

\begin{abstract}
The high-end equipment intelligent manufacturing (HEIM) industry is of strategic importance to national and economic security. Engineering management (EM) for HEIM is a complex, innovative process that integrates natural science, technology, management science, social science, and the human spirit. Newgeneration information technology (IT), including the internet, cloud computing, big data, and artificial intelligence, have made a remarkable influence on HEIM and its engineering management activities, such as product system construction, product life cycle management, manufacturing resources organization, manufacturing model innovation, and reconstruction of the enterprise ecosystem. Engineering management for HEIM is a key topic at the frontier of international academic research. This study systematically reviews the current research on issues pertaining to engineering management for HEIM under
\end{abstract}

Received June 1, 2018; accepted July 14, 2018

Shanlin YANG $(\bowtie)$

School of Management, Hefei University of Technology, Hefei 230009, China

E-mail: yangs1@hfut.edu.cn

Jianmin WANG

School of Software, Tsinghua University, Beijing 100084, China

Leyuan SHI

Department of Industrial Engineering \& Management, Peking University, Beijing 100871, China

Yuejin TAN

College of Systems Engineering, National University of Defense Technology, Changsha 410073, China

Fei QIAO

School of Electronics and Information Engineering, Tongji University, Shanghai 200092, China

This work is funded by the National Natural Science Foundation of China (Grant Nos. 71690230, 71690231, 71690232, 71690233, 71690234, and 71690235), and supported by Innovative Research Groups of the National Natural Science Foundation of China (Grant No. 71521001). the new-generation IT environment. These issues include cross-lifecycle management, network collaboration management, task integration management of innovative development, operation optimization of smart factories, quality and reliability management, information management, and intelligent decision making. The challenges presented by these issues and potential research opportunities are also summarized and discussed.

Keywords high-end equipment, intelligent manufacturing, engineering management, information technology

\section{Introduction}

High-end equipment manufacturing (HEM) is a core part of the industrial and equipment manufacturing value chain. It is an important indication of a nation's capabilities in science and technology and comprehensive power. It also guarantees technological advancements and industrial transformation and growth at the national level. The industry is of strategic importance to national defense and economic security. High-end equipment (HE) refers to a type of technical equipment with advanced technology, large capital investment, and a long life span. It is applicable in many disciplines, and its production must be organized with cross-domain, cross-industry, and crossregional manufacturing resources. HE can be classified as basic, specialized, and outfit equipment. Examples include high-end computer numerical control machine tools, largescale and high-end forming equipment, large-scale integrated circuit manufacturing equipment and other basic equipment such as large-scale scientific instruments, civil aircraft, and high-speed electric multiple units. HE also includes aerospace, marine engineering, modern military, and other special equipment, as well as petrochemicals, large-scale power, and other outfit equipment.

Currently, new-generation information technology (IT), including the internet, cloud computing, big data, artificial intelligence, and block chains, is integrated into the 
manufacturing industry. This integration stimulates the development of the intelligent manufacturing industry, which is the main feature of this new scientific, technological, and industrial revolution. Intelligent manufacturing is increasingly important for the development and transformation of HEM industries and promotes an evolution to intelligent, internet-connected, and serviceoriented HE. The traditional HEM innovation system is reorganized using cross-domain and networked innovation platforms, namely, crowd innovation and crowdsourcing models, which have considerably influenced traditional management ideas, production modes, and business models. Moreover, new-generation IT plays a critical role in the innovation-driven development of HEM.

In recent years, developed countries and regions have accelerated the development of science and technology and the industry, with HEM in the internet and big data environment being one of the most important aspects of national competition. Strategies for re-industrialization have correspondingly been proposed. For example, the United States has formulated the "Advanced Manufacturing Partner Program" and the "Advanced Manufacturing Country Strategic Plan" while Germany has proposed "Industry 4.0." The UK, France, and Japan have also promulgated a series of strategic initiatives for the development of HEM, such as "British Manufacturing 2050," the "New Industrial Revitalization Plan," and the "2014 Manufacturing White Paper." The Chinese government has proposed the implementation of "Made in China 2025" and the "Internet Plus" action plan, a development plan of "New Generation of Artificial Intelligence," guidelines for deepening "Internet Plus Advanced Manufacturing" for the development of the industrial internet, and a series of strategic plans to promote the deep integration of manufacturing technology and IT.

Many world-class HEM companies are seriously paying attention to the remarkable changes of the equipment manufacturing industry caused by emerging IT. These companies apply such emerging IT to their HE products, manufacturing processes, and management to gain position in the industry value chain. For example, Tesla in the US uses automotive intelligence to design and develop smartconnected new energy automotive products. Specifically, the internet of vehicle technology enables product data to be shared with any other products, operating systems, manufacturers, and users, thereby contributing to the evolution of automotive products into a series of integrated services that can improve customer satisfaction. Airbus SAS has recently built the largest and most efficient supply chain system in global manufacturing by applying the Internet of Things (IoT) technology to logistic areas, such as raw material procurement, inventory storage, and product sales. Siemens AG and Mitsubishi Corporation have used IoT and big data technologies to achieve full automation control and digital manufacturing management, including the development, production, service, and remanufacturing of the products in their entire life cycle. This approach improves the automation level and efficiency of manufacturing processes.

The deep integration of new-generation IT and the manufacturing industry has greatly influenced the HEM industry, thereby changing the relationships among HEM systems, people, organizations, society, and the environment. At the same time, the HE industry value chain has expanded, as reflected by its widespread influence on the economy, society, and the environment. Intensive technological innovations and collaborations emerge in the processes of product development, production, and service. Such changes prompt a new set of features and development trends and ultimately initiate major development in the management of HE for intelligent manufacturing projects.

Engineering management for high-end equipment intelligent manufacturing (HEIM) is a complex innovative process that deeply integrates natural science, technologies, management science, social science, and the human spirit. In this process, people combine various technical, human, and material resources and diverse ideas to develop HE with unique market appeal and intensive knowledge base and technology. Engineering management for HEIM is a type of complex system engineering with multiple levels, disciplines, and agents that are deeply coupled. When used to deal with theoretical and technical problems, this type of system engineering should be applied to engineering practices. Moreover, engineering management for HEIM requires breakthroughs not only in individual engineering technology but also in the overall technology based on comprehensive coordination. It is also a type of innovative activity that is systematic, time sensitive, collaborative, and risky. The precise analysis of product demand, the strategic selection of project portfolio, the $R \& D$ organization of key technologies, the classification and optimization of manufacturing processes, the dynamic scheduling of manufacturing resources, the cooperative control of multiple agents and departments, the dynamic decision making regarding manufacturing processes, and the scientific construction of information systems are management problems that must be addressed in the process of developing $\mathrm{HE}$ with independent intellectual property rights. Therefore, the integration of scientific, technological, and organizational management, as well as institutional mechanism innovations, through effective EM is necessary to realize comprehensive integration innovation and thereby achieve project goals.

The present study investigates the effects of newgeneration IT on $\mathrm{HE}$ and intelligent manufacturing engineering and then analyzes the key challenges and problems in management activities, including crosslifecycle management, network collaboration management, task integration management of innovative development, operation optimization of smart factories, quality and reliability management, information management, and 
intelligent decision making for HEIM. Then, the current research status, future research opportunities, and the directions of each issue are explored. Figure 1 shows the relationship among the key issues on engineering management for HEIM.

\section{Remarkable influence of new-generation IT on engineering management for HEIM}

\subsection{Changes in the HEIM industry}

New-generation IT is reshaping manufacturing industries and has introduced collective technological revolution characterized by greenness, intelligence, and ubiquity in almost all fields. New technological and industrial revolutions are emerging. Globally, new IT has become an integral part of the HEM innovation system. New enterprise-user relationships have been formulated due to the rapid and easy interaction between humans and the internet. Moreover, the organization and management modes of HEM are changing. All of these phenomena have promoted radical innovations in technology and management that exert a profound influence on the manufacturing model and development strategy of the HEM industry.

Construction technology for product system. Newgeneration IT is continuously integrated into HE products and is an indispensable part of the product system, which gradually evolves products into intelligent products and smart, connected systems. Ultimately, the intelligence level, performance, and application scope of HE have advanced, improved, and expanded, respectively.

Product life cycle management. New-generation IT is applied to the entire life cycle of HEM processes, including product $\mathrm{R} \& \mathrm{D}$, production, usage, and maintenance remanufacturing activities. This application improves the innovation design capabilities of $\mathrm{HE}$ and the intelligence of production and maintenance, reduces the manufacturing time and costs, and decreases the risk of manufacturing.

Organization of manufacturing resources. Newgeneration IT is widely used in the collaborative processes among suppliers, vendors, and collaborators, thereby building a global network for manufacturing and optimizing the value chain and network. Thus, market demands can increase rapidly, global manufacturing resources can be organized efficiently, and the utilization efficiency of these resources can be improved.

Innovation in the manufacturing business model. New-generation IT accelerates the servitization process of HEM. All services are brought into the sales scope, and the boundary between products and services has become less obvious. The existing model of physical product-oriented sales is projected to be replaced by a model of serviceoriented sales based on physical products.

Reconstruction of the enterprise ecosystem. The manufacturing value network is the natural ecological environment for node enterprises. Under the new-generation IT environment, restructuring the production factors of $\mathrm{HE}$

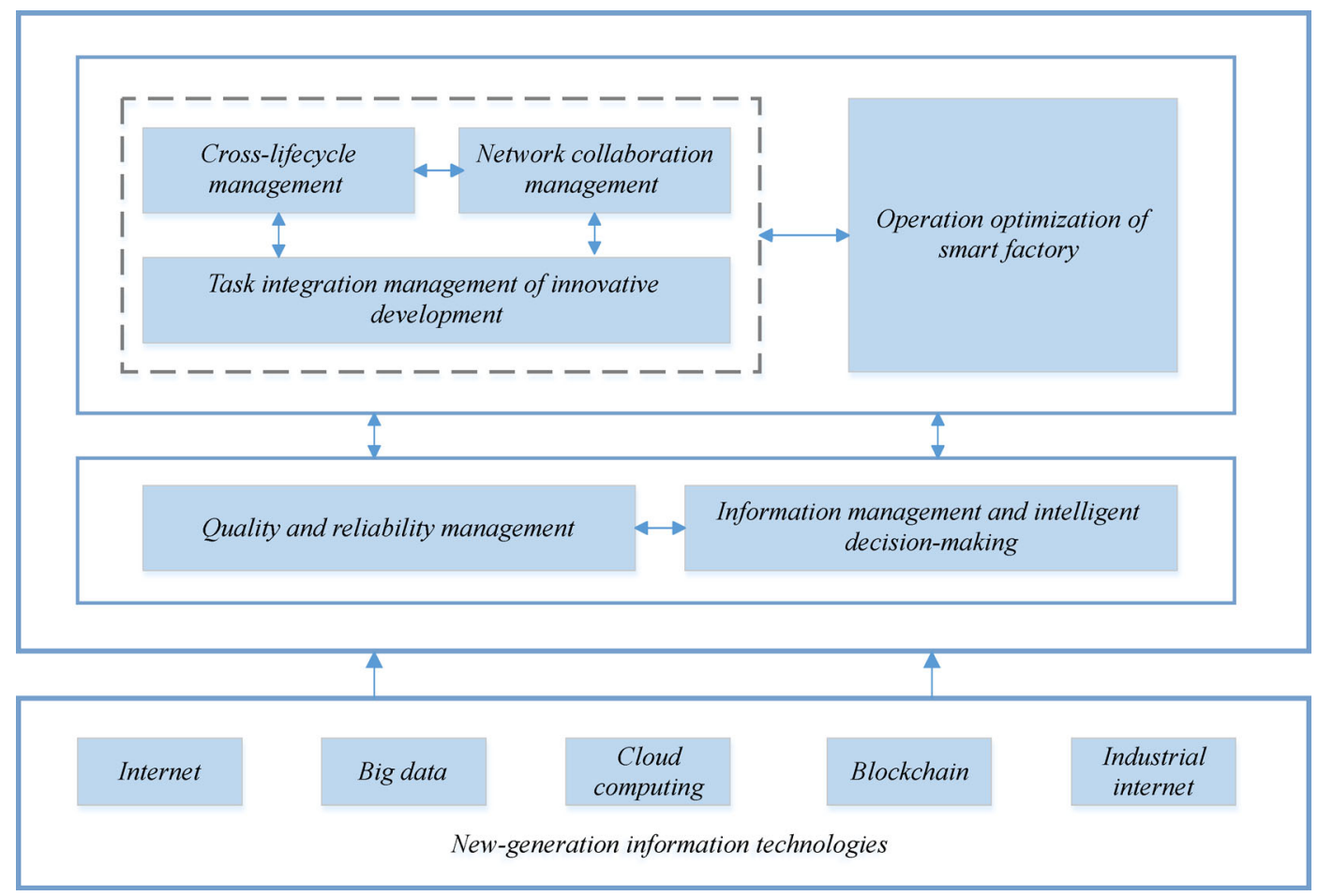

Fig. 1 Relationship among the key issues on engineering management for HEIM 
companies is inevitable and is expected to lead to the reconstruction and optimization of the enterprise ecosystem.

\subsection{Trends and new characteristics}

The deep integration between new-generation IT and the manufacturing industry is changing the relationship among manufacturing systems, people, organizations, society, and the environment. This integration is expanding the value chain of HE products, thereby complicating the technologies of manufacturing. The influence of this phenomenon on the development of society and the economy is extensive, and collaborations in development, production, and services are increasingly intense. Trends in globalization, collaboration, and intelligence are emerging, along with new manufacturing models, such as large-scale customization and service-based manufacturing and collaborations. The HEIM process presents new features.

Diversification of manufacturing data. HEM information product types are diverse. Business data include concept design, detailed design, manufacturing process, and packaging and transportation data generated from internal and external enterprises and the IoT. Operation and maintenance data include operation status, maintenance plan, and service evaluation data. Therefore, manufacturing data are currently characterized by complex sources, rich types, large volumes, low value density, and rapid updates.

Servitization of manufacturing products. The rapid development of the internet and big data, mobile computing, the IoT, cloud computing, and other IT tools has enabled HE products to evolve into smart-connected products. In this context, HE products can be converted into a series of integrated services to provide new value for users throughout the product life cycle.

Personalization of manufacturing mode. The rapid development of new-generation IT provides manufacturers with a way to ensure timely communication with customers. This development enables companies to meet customer needs rapidly and accurately and achieve largescale customized production at a low cost according to customer requirements.

Coordination of manufacturing process. The competition for HEM under the environment of new-generation IT is no longer between individual enterprises but among the entire value network. Enterprises must integrate the value chain horizontally, establish alliances with manufacturing companies vertically, and use open innovation platforms to converge on globalization manufacturing resources and socialized smart resources to finally engage in collaborations in the manufacturing process.

Globalization of manufacturing resources. In the new-generation IT environment, the entire enterprise is regarded as the main body of manufacturing resources. It is also considered to be made up of independent functional units, such as equipment, production lines, and production workshops, which can be converted into manufacturing resources. HEM-related companies apply their own manufacturing resources by utilizing IT to participate in the global collaborative manufacturing process and realize the globalization of manufacturing resources.

These new features have changed the interactive methods and behavior methods among individuals, organizations, and resources in the HEM process. A series of changes in the management of HEM projects have been implemented. (i) Organizational forms have evolved from a single company to a cross-border manufacturing ecosystem based on the value chain and network. (ii) Operational decision-making models have been transformed from event-driven models to data-driven real-time decision-making models. (iii) Collaborative manufacturing methods have moved from static collaborative manufacturing based on the supply chain to dynamic, adaptive shaft-spoke collaborative manufacturing. (iv) Finally, the manufacturing production mode has shifted from large-scale manufacturing production to large-scale personalized manufacturing driven by data and services.

In summary, HEIM is system engineering with deep integration of technology and management, and its core technology is engineering management. Project management theory and technical problems that must be solved in the development of $\mathrm{HE}$ with independent intellectual property rights include cross-lifecycle management, network collaboration management, task integration management of innovative development, operation optimization of smart factories, quality and reliability management, information management, and intelligent decision making for HEIM. The scientific management of HEIM engineering facilitates the coordination of the relationships among engineering systems and the project environment, science and technology, talent and capital and other resources, and the engineering activities in various departments and units. With such coordination, achieving goals is relatively easy. In this regard, the value goals, management solutions, and theoretical approaches of HEIM must be analyzed from a broad perspective.

\section{Cross-lifecycle management of HEIM}

Since the beginning of the 21 st century, the cross-lifecycle management of HEIM has broken through the barriers of traditional design, manufacturing, and service. Modeling and optimizing HEIM ecosystems have been performed chronologically at the global level. With the development of new manufacturing modes such as Industry 4.0, the industrial internet, and networked manufacturing, the cross-lifecycle management of HEIM has become a leading research direction for management concepts and technological changes in the HEIM field. This section analyzes the present research on HEIM carried out by 
domestic and foreign academia and industries under four topics (Fig. 2).

3.1 Integration and optimization of cross-lifecycle business process in HEIM

The integration and optimization of the cross-lifecycle business process in HEIM covers development and design, production and manufacturing, operation and maintenance services, and other related business process management (BPM) stages of HE. Under the internet and big data environment, the demand for decentralized manufacturing for networked collaborative manufacturing is increasing, and the production factors and production processes of an enterprise are expected to undergo strategic reorganization. Equipment manufacturing enterprises need to understand the situation, carry out the strategic transformation of business processes in a timely manner, and build a BPM platform that adapts to a networked collaborative manufacturing environment (McElheran, 2015). The present situation of domestic and overseas research and development is analyzed on the basis of two aspects.

Integration of cross-lifecycle business processes. Tanriverdi et al. (2007) surveyed 93 large- and mediumsized US firms to explore how enterprises select the outsourcing mechanism of their business processes. Whitaker et al. (2010) developed a conceptual model to identify and analyze the corporate level characteristics that promote the outsourcing of domestic and overseas business processes. Guo et al. (2014) presented a data flow model of workflow management and mathematics to solve the independent multi-stakeholder problem of data exchange in business process integration under a dynamic environment. La Rosa et al. (2013) investigated the construction of an integrated business process model from the process model collection of shared public fragments to optimize the most frequently occurring model fragments.

Optimization of cross-lifecycle business processes. Gröger et al. (2012) introduced a complete concept of a manufacturing process warehouse that can serve as a core part of an advanced manufacturing analysis platform. Sohail et al. (2015) explained that a process warehouse resource assessment method can be used for process improvement. Nguyen et al. (2016) proposed the evolution of process performance through the concept of staged phase flow. Senderovich et al. (2016) proposed the operational performance improvement method according to queuing network-based conformance inspections and deviation origin analysis. Sun et al. (2017) adopted a mirror matrix method based on footprint variant and parallel programming that optimizes the original process according to the log.

The current research is mainly focused on aspects that include heterogeneous business process matching and sharing, cross-enterprise business process integration, improvement, and outsourcing mechanisms. In the future, an in-depth study must explore the flexible integration and intelligent optimization of cross-lifecycle heterogeneous business processes in HEIM on the basis of similarity measurements and massive operational logs, respectively.

\subsection{Cross-lifecycle data integration and traceability in HEIM}

Cross-lifecycle data integration and traceability in HEIM

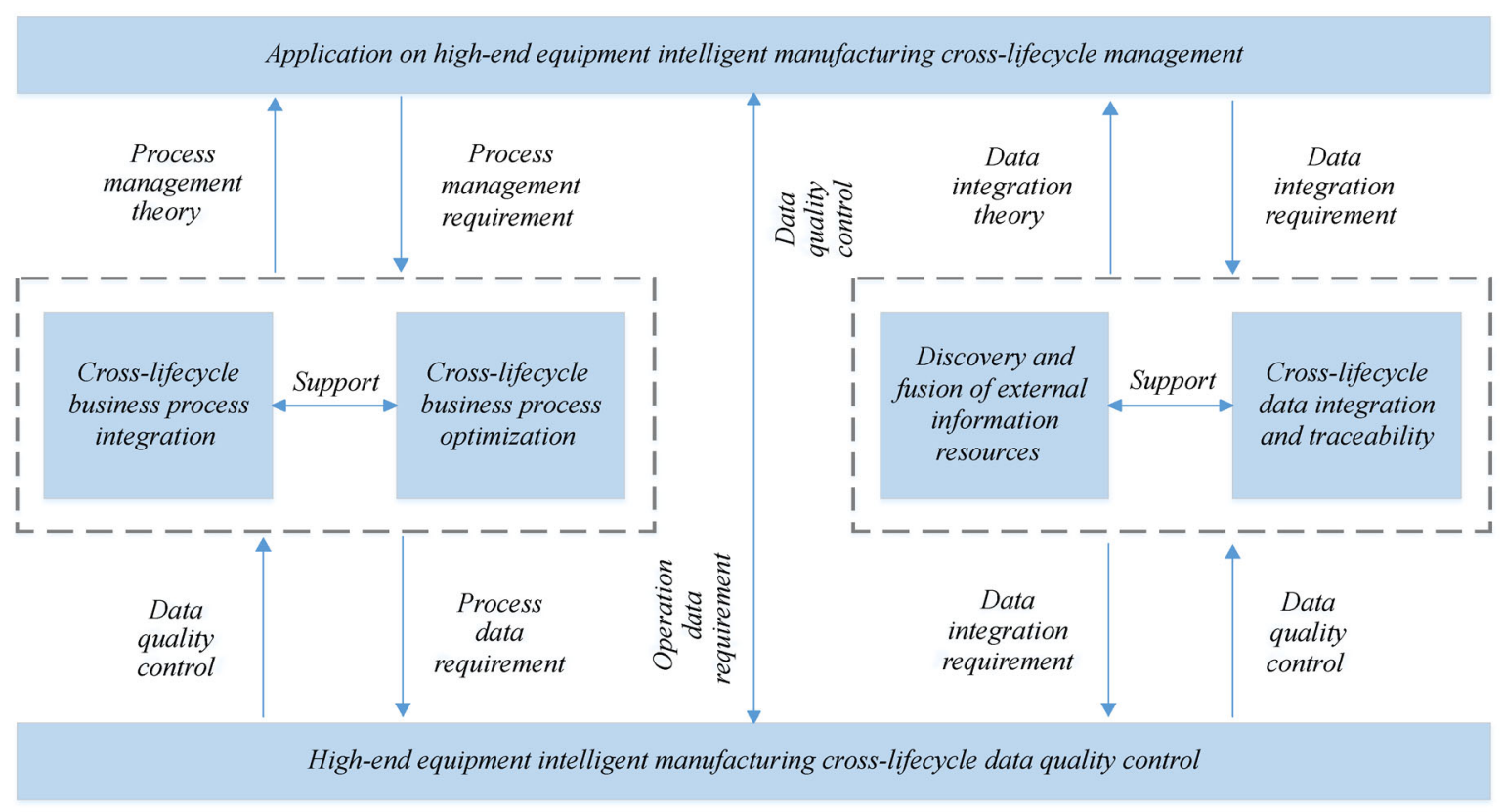

Fig. 2 Key research issues in cross-lifecycle management of HEIM engineering 
cover multi-source, multi-type, and multi-modal data sources from all stages of product development, design, manufacturing, use, and recovery. Through data analysis and mining, an effective model is established to realize data integration and traceability management. This section provides an analysis of the development status of domestic and foreign research from three aspects.

Cross-lifecycle data integration in HEIM. Morris et al. (2004) focused on data integration at different stages of the equipment life cycle and investigated the integration of equipment life cycle data, data matching, data synthesis, and information service. Maltzahn and Anderl (2011) proposed a method to generate bill of material (BOM) on the basis of the requirement specification for reusing product knowledge semi-automatically. Zhou and Wang (2009) proposed the integration of multi-source heterogeneous data on the basis of middleware.

Cross-lifecycle data traceability in HEIM. Xu et al. (2010) focused on the problem of closed-loop tracking and feedback of equipment information and proposed a data tracing framework composed of system, process, and data layers. Liang and Wang (2013) examined the content recommendation of webpages based on users' usage logs using origin tracking theory. Zhang et al. (2012) proposed a rule-based traceability algorithm for data origins. Tang and Yun (2008) established a quality data integration model and emphasized the traceability of quality data.

Cross-lifecycle multimodal data correlation in HEIM. Yazdi and Kahani (2014) analyzed a large body of semantic data to conduct association rule mining and enrich the semantics with the meaning of ontology. Nugraheni et al. (2016) presented a framework to develop a semantic data warehouse that can deal with incomplete and heterogeneous data. Bao et al. (2014) designed data integration and fusion architecture for the information island problems brought about by massive heterogeneous data and subsequently proposed an algorithm to deal with conflicts by using metadata.

Shortcomings are still observed in the integration and traceability of cross-lifecycle data in HEIM. In terms of data integration theory, the current research mainly focuses on product life cycle maintenance based on IT. In terms of data traceability theory, a variety of research on scientific workflow, semantic web, and biology is available, but related works on the origins of equipment cross-lifecycle data are limited. In terms of multi-modal data correlation theory, studies on the integration of heterogenous crosslifecycle data with multiple sources, organic data correlation by means of semantic integration, and masking the physical and logical differences between data are also available.

3.3 Discovery and fusion of external information resources for HEIM

In the internet environment, data sources are highly dispersed and are extremely complicated and fragmented. The large volumes, complex correlations, and diverse goals of internet data strongly contradict the management approach to internal data with high concentrations, regular correlations, and clear goals. However, once organic integration is achieved, the internal information management of HE enterprises can be injected with strong vitality and impetus for innovation (Winnig, 2016). The present situation of domestic and overseas research and development is analyzed from the following aspects.

Discovery and acquisition of external information resources for HEIM. Wang et al. (2017) conceptualized MRO II and proposed the comprehensive utilization of internal and external information in enterprises. Hegge and Wortmann (1991) described the general product model and proposed a basic management plan around the correlation of life cycle information. Romanowski and Nagi (2005) proposed that material lists are modeled by disordered trees and that a quantitative method is used to compare structural differences by distance measurement. As a result of the complexity of external internet information, a traditional relational database cannot meet the requirements of extraction and fusion. Therefore, Angles and Gutierrez (2008) examined various types of graph databases and reviewed their development and evolution.

Integration of external information resources for HEIM. Paulheim (2017) extensively reviewed the evolution and application of knowledge graphs. Lim et al. (2011) presented the idea of using semantic annotation to integrate different product data models and build a connection on top of these product models. Yang et al. (2016) proposed BOM-based ontology architecture to aid the design of intersectoral auxiliary systems. Ding et al. (2014) and Wang et al. (2017) used big data technology to extract useful information from industrial monitoring data to support the prediction of part demands, abnormal individuals, and so on. With the introduction of industrial internet by GE and Siemens, attention was given to the integration of internal and external information in the industrial field. GE Digital began to manage the products in its asset data service and developed a graph database for asset management on the basis of Cassandra's distributed data graph.

The discovery and fusion of external information resources for HEIM is still in its infancy, and further studies on how to define theories, methods, and applications effectively should be performed. In the future, the discovery and integration of external information resources for HEIM based on knowledge graphs will become an important development trend with the popularization of industrial internet.

\subsection{Quality control of cross-lifecycle data for HEIM}

Quality problems are particularly critical in cross-lifecycle data for HEIM. Batini et al. (2009) showed that identifying 
and resolving conflicts and inconsistencies in data have become an important research topic. Most existing cleaning techniques for traditional relational data are not applicable to quality problems in the cross-lifecycle data for HEIM, particularly the quality of sequence data generated by HE, such as wind power units. This section analyzes the development status of domestic and overseas research from three aspects.

Data quality measurement theory and profiling. Abedjan et al. (2015) investigated the latest data profiling methods, including simple statistical measures, singlecolumn data analysis indicators, and multi-column correlation analysis methods. Song and Chen (2011) proposed differential dependencies and introduced a similarity measure to both sides of the constraint rule. Chu et al. (2013) proposed denial constraints to profile data size equality.

Poor data cleaning and correction. Kolahi et al. (2009) found that the minimum data repair problem based on functional dependencies is a nondeterministic polynomial (NP) hard problem that requires the design of an efficient approximation repair algorithm. Zhang et al. (2010) proposed the use of absolutely correct master data to modify data with editing rules. In addition to the method based on the constraint rule, Bergman et al. (2015) considered user participation by utilizing user interaction and feedback on query results to clean up data.

Data alignment technology and optimization of data acquisition. Zhang et al. (2010) showed that time labels for sequence data often have errors due to various factors in a distributed environment. Zhu et al. (2014) investigated the matching alignment of discrete event sequence data. According to the alignment of time series data, Müller (2007) introduced dynamic time warping by adjusting the alignment of two time series dynamically to minimize the corresponding point distance.

Therefore, the existing profiling analysis technology for traditional relational data cannot be directly applied to the HE operation and maintenance service (HEOMS) data of sequential data type. Moreover, neither data cleansing nor repair techniques based on functional dependencies are applicable to sequence data. The alignment of sequence data should be explored further on the basis of the existing discrete event data alignment.

\subsection{Challenges and research opportunities}

Four problems exist in the cross-lifecycle management of HEIM in the internet and big data environment. (i) As a result of the intricacies of products themselves, the complexity of HEIM determines the level of difficulty of the life cycle manufacturing process, which involves the large-scale multi-level business process integration and optimization problem in cross-enterprise collaboration. (ii) Large amounts of data are generated and consumed during the HEIM life cycle, and the bidirectional correlation and traceability of cross-stage, long-period, and multi-source heterogeneous data are inevitable technical challenges. (iii) An open source and sharing economic model enables HE to realize cross-border data integration and utilization, and the discovery and integration of external and transboundary information resources of HEIM have become technical hot spots. (iv) The quality of HEIM data are directly related to the quality of engineering management for and decision making in HEIM, and innovating the quality control method for ensuring the quality of cross-lifecycle data quality has emerged as a pressing challenge. The main research topics are as follows.

- Integration and optimization theory for crosslifecycle business processes of HEIM in the internet and big data environment: Unified modeling and heterogeneous integration theory and technology of crosslifecycle business processes in HEIM; log data collection for cross-lifecycle business processes and correlation technology; measurement of key indicators and optimization theory for cross-lifecycle processes based on business $\log$ data; improvement strategy for business process models based on business log mining.

- Data integration and traceability of HEIM in internet and big data environment: A neutral $\mathrm{BOM}$ automatic generation method, cross-lifecycle data correlation analysis theory, and change impact analysis technology for BOM instance; modeling of the origin of complex event data of HEOMS, data origin descriptions, and data origin tracing methods; cross-lifecycle time series data with high throughput, unstructured data, and correlation analysis theory for BOM diagram data; multi-modal semantic fusion analysis theory.

- Discovery and fusion theory for external information resources of HEIM in the internet and big data environment: Method of ontology generation in HEIM based on material inventory characteristics; external data discovery and collection method for internal and external life cycle data of enterprises in HEIM; development of theoretical framework of information cross integration in the entire life cycle of complex equipment based on semantics through concept knowledge graph generation and utilization method based on collection information.

- Data quality control theory of HEIM in the internet and big data environment: Research on quality control theory of service data quality of HE; methods for data quality measurement and profiling theory of HEOMS; a method for data cleaning and repair as part of HEOMS; an optimization strategy for HEOMS data collection; formation of mechanism for HEOMS data flow monitoring.

\section{Network collaboration management for HEIM}

Internet and big data technologies have revolutionized the network cooperation in HEM by allowing a full integration 
of manufacturing processes and real-time data. This development has offered a new background for academic research on cooperative management theory in HEM. The research conducted by domestic and foreign scholars can be categorized into the following: (i) end-to-end integration and collaborative optimization theory of HEM supply chain, (ii) construction of a HEM service chain and cooperative scheduling method, (iii) value modeling and evaluation of the HEM network, and (iv) prediction and dynamic evolution of HEM.

The recent developments in these areas are discussed in the following sections. The relationships are shown in Fig. 3.

4.1 End-to-end integration and collaborative optimization in the HEM supply chain

Data integration and collaborative optimization in the HEM supply chain aims to shorten the production cycle and improve its value by balancing the relationships among costs, revenue, and service time. Supply chain contracts are the basis of the collaborative optimization of the supply chain. An important research area is how to coordinate the procurement, distribution, and service strategies of players in the supply chain through contracts. The accurate definition, measurement, and evaluation of supply chain risks are essential to enhance the robustness and effectiveness of the HEM supply chain. In the area of supply chain contracts in manufacturing enterprises, Sun and Debo (2014) discussed supply chain profit maximization problems with long-term procurement contracts in a turbulent market environment through the cooperation of supply chain players. Zhang et al. (2013), Zhang (2010), and Kayıs et al. (2012) investigated the issues in designing supply chain contracts to control quality, reliability, and costs in the supply chain cooperation under information asymmetry. Kim and Netessine (2013) and Roels et al. (2010) discussed the impact of supply chain information sharing and supply chain contracts on cooperation in product design phases. Arshinder et al. (2011) reviewed the literature on supply chain collaborative optimization in manufacturing enterprises and explained that designing collaboration strategies for supply chain utility maximization is necessary. Xu and Zhai (2010) examined a twophase supply chain collaboration problem. They used fuzzy numbers to capture the demand and prove that the expected profit of the supply chain with cooperation is greater than that without cooperation. Foreman et al. (2010) took Dell as a research case and minimized the cost of the supply chain by controlling the supplier's distribution path and inventory in the distribution network from the view of the center-to-central manufacturing. Numerical results reveal that the approach reduces the supply chain cost by $60 \%$. In the area of risk control in the operations management of manufacturing supply chains, Heckmann et al. (2015) performed a comprehensive literature review of the definitions, methods, and models related to the risk of supply chains. They claimed that the definition of "supply chain risk" in the existing research is fuzzy and unquantifiable. The measurement indices included variance and standard deviation, and a risk threshold analysis method was adopted. The formulation and optimization methodologies included mathematical programming models and heuristic algorithms. Tummala and

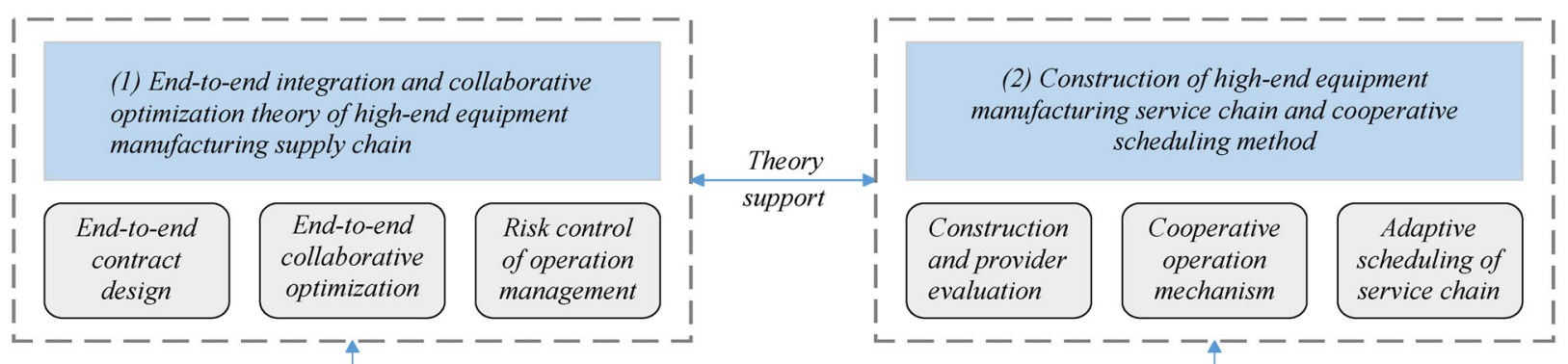

(1) and (2) support theoretic basis to (3) and (4);

(3) and (4) supplement (1) and (2)
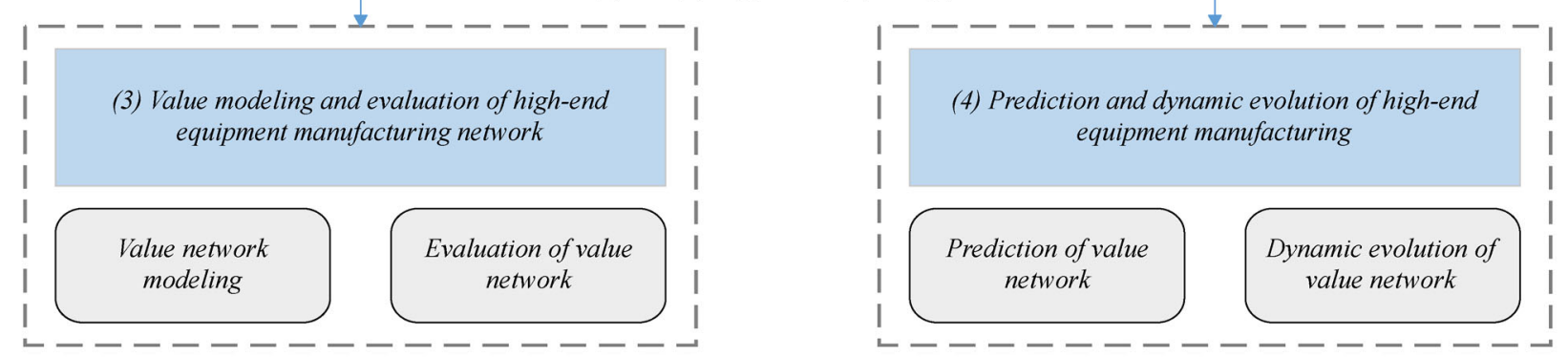

Fig. 3 Key research issues in network cooperative management for HEIM 
Schoenherr (2011) reviewed the literature on supply chain risk management from the aspects of risk identification, measurement, assessment, and management.

This review shows that the literature focuses on solving the problem of cooperative optimization in the traditional supply chain and that research on the HEM supply chain is limited. In contrast to the traditional manufacturing supply chain, in which the product procurement cost is a primary concern, the HEM supply chain is sought to be optimized in terms of contract design with consideration of product quality and production cycle. Compared with the traditional supplier-retailer supply chain network, the cooperation network becomes complicated in the HEM supply chain, in which the supply chain contract design, cooperative optimization, and risk control form an interactive closed loop. Contracts and collaborative optimization objectives can affect the formulation of risk models and evaluation results. Moreover, risk control measures are embodied in the constraints of contract design and cooperative optimization problems. Supply chain utility achieves optimum results through close loop regulation. Existing research discusses risk control without considering other phases in the high-end supply chain optimization problem. A comprehensive study on contract design, collaborative optimization, and risk control in the HEM supply chain is an important task in the future.

4.2 Construction of HEM service chain and cooperative scheduling method

The manufacturing service chain is a collection of intermediate services for a manufacturing enterprise during the entire life cycle of a product. The manufacturing service chain is dynamic, complex, and temporal. According to advanced management theories for the activities of manufacturing enterprises, enterprises are the customers in the manufacturing service chain, products are the service targets, information is the foundation, service is the purpose, and the service chain integrates manufacturing and service. In the area of construction of the manufacturing service chain and evaluation of service providers, Ching et al. (2011), Cao et al. (2013), and Wei et al. (2013) investigated the problem of service ability management; although the numbers of service providers and retailers they reviewed were different, they all aimed to maximize service quality. Jin and Ryan (2012) defined a supplier scoring function that includes a random probability selection model constructed by analyzing the competitive relationship of suppliers. In the area of outsourcing and cooperation in the manufacturing service chain, Zhou and Chen (2012) claimed that outsourcing can reduce supply chain costs and competition through scale effects. Enterprises can focus on the core business to improve service levels and cope with the uncertainty of demand with outsourcing. Liang and Atkins (2013) investigated the combination of outsourcing and service-level contracts using principal-agent theory. In the area of cooperative operation in production scheduling and service chains, Liu et al. (2013) studied the impact of logistic service quality on service chain cooperation. Stavrulaki and Davis (2014) reviewed the strategic decision problems of service chains. Liu and Xie (2013) examined the multi-stage characteristics of logistic service cooperation and proposed a threelevel logistic service quality cooperation model for the service supply chain. Yeung et al. (2011) considered delivery time, logistics time, and inventory costs and a system profit maximization problem that includes two levels of centralized and decentralized manufacturers.

This review reveals that the existing research focuses on the outsourcing and collaboration of traditional manufacturing supply chains. However, under a big data environment, the HE customization requirements are higher, the production batch is smaller, and the internal and external cooperative environments of manufacturers are more complex than those under traditional environments. For cooperative operation and scheduling in the service chain of equipment manufacturing, HEM is characterized by small inventory scales, simple logistics, and complex supply chain networks. Research on combining enterprise scheduling and service chain operation optimization is rare, and the constraints of time and space costs have not been considered. Future research could consider the characteristics of HEM service chains. Models and algorithms that achieve high efficiency convergence and obtain global optimal values are highly desirable.

\subsection{Value network modeling and evaluation for HEM}

The value network of HEM is complex and is formed by cross-connecting various value elements in the manufacturing supply chain and the service chain. Constructing a value network model that can capture the unique characteristics of HEM and accurately quantifying each element of the value network are essential given the large uncertainties in the external environment and internal interactions. A dynamic and quantitative evaluation of value networks is also critical to the dynamic and uncertain behavior of each element of the value network. Value network modeling and evaluation has been studied extensively in the existing literature.

Value network modeling. Bititci et al. (2004) proposed a model containing value transactions and different collaboration features for collaborative environments. Jayaram et al. (2004) constructed a structural equilibrium model to link initial conditions to a value creation mechanism. Zhang (2006) studied an economic problem that includes multiple heterogeneous supply chains and constructed a corresponding network model. Wang et al. (2008) initially divided the industrial value chain into several stages and then used a directed connected graph to 
express the results intuitively. Finally, an industrial value model was established through an industrial value matrix. Byramjee et al. (2010) proposed a total value model for business systems to study the role of relationship quality in mitigating individual values.

Quantitative evaluation of value networks. MartinezHernandez (2003) proposed a value cube framework to describe how organizations should collaborate and manage their operations, resources, production capacity, and competitiveness to create value. Bititci et al. (2004) studied the theory of value creation in collaborative environments and defined two values, namely, internal (shareholder value) and external values (value reference). Reiner (2005) studied the customer-oriented promotion and supply chain process assessment through simulation models. Wang et al. (2008) proposed two evaluation criteria, namely, throughput and reliability, using an industry value matrix to evaluate the competitiveness of a specific industrial value chain. Saranga and Moser (2010) developed a comprehensive performance measurement framework by using the classic two-stage value chain data envelopment analysis models.

The existing studies on value change modeling and quantitative evaluation for supply and service chains mainly target general manufacturing processes. In addition, the evaluation systems mainly focus on qualitative indicators and rarely consider quantitative evaluation tools, which are highly desirable. On the contrary, HEM has unique characteristics, such as diverse customer demands, collaborative manufacturing processes, and socialized manufacturing capabilities. It requires multilevel manufacturing resource self-organization and integration across the value chain. With the advent of industry 4.0, the traditional supply chains have evolved toward a highly connected supply chain ecosystem that is fully "transparent" to all the players involved. Therefore, addressing the impact of the IoT and big data techniques is necessary when constructing value network models. The dynamic evolution process of the value network model and the evaluation and real-time feedback of indicators should be comprehensively considered to achieve an efficient and dynamic quantitative assessment of different value networks.

\subsection{Dynamic evolution and prediction of value networks in HEM}

The value networks in HEM have undergone significant changes in the context of the internet and big data environments. The network structure of various resources in the manufacturing ecosystem has presented a complicated, dynamic, and diversified form. Key elements change constantly over time due to the intensive interaction among various internal and external resources. Therefore, a comprehensive and quantitative knowledge of corresponding network values is necessary for HEM systems. In addition, key elements and indicators of future value networks should be predicted dynamically, and an accurate judgment of changes in the overall network structure should be formed. The main relevant research areas are as follows.

Prediction of value network factors and key indexes. Oh and Özer (2012) studied the influence of time changes on forecasting under uncertain conditions by establishing a generalized model that considers the prediction of multiple product makers for the same product. Nasser and Turcic (2017) considered the demand forecast for manufacturers when retailers hold comprehensive private sales information with uncertainty and subsequently proposed a policy in which manufacturers could temporarily reduce product price. Dalal et al. (2014) applied the concept of a multiagent system in the architecture of the demand forecasting tool, which can handle the complexities and limitations of the traditional demand forecasting system used in a realtime supply chain management system. Williams and Waller (2010) considered a case in which suppliers can access seller data and found that demand signals as prediction resources are more useful than order data.

Dynamic evolution and mechanism of value networks. Guide and van Wassenhove (2009) proposed four aspects for closed-loop supply chain evolution: Remanufacturing, remanufacturing to reversible logistics, reversible supply chain coordination, and evolution in the direction of markets and prices. Lusch et al. (2010) proposed a robust model as a necessary service agent from the perspective of service-oriented value networks. Marsillac and Roh (2014) considered interactions among products, processes, and designs in the supply chain and pointed out that the changes in product design cause a series of changes in production operations. Cheng et al. (2011) examined factory changes in a manufacturing network and demonstrated that changes in a manufacturing plant affect the subsequent network of others in the manufacturing network.

In summary, studies on the prediction and evolution of HEM value networks are limited. Forecasting indicators in the literature mainly focus on demand and sales forecasting and do not consider the characteristics of $\mathrm{HE}$ value networks. Existing studies have not integrated the internet and big data into value networks to conduct monitoring and anomaly detection. HEM is characterized by huge data, high dimensionality, complex networks, and key elements that constantly change over time due to the interactions of various internal and external resources. Therefore, considering various uncertainties and correlations is necessary when studying HEM value networks to form a comprehensive and quantitative knowledge of the network value of systems. This consideration will help to dynamically predict the key elements and indicators of future value networks and form an accurate judgment of the overall changes in network structure. 


\subsection{Challenges and research opportunities}

HEM faces new situations and opportunities in policy orientation and the industrial structure of global competition. Thus, establishing a collaborative management theory for HEM networks in the context of the internet and big data technologies is necessary. This theoretical foundation is crucial for the reform and development of the HEM industry in China. Such theory is also closely related to the improvement of overall operational management levels and the core competitiveness of the country. Therefore, in the dimensions of time, space, and tasks, a thorough study of the major scientific issues in the collaborative management of HEM networks under the internet and big data environments is required. Current research includes the end-to-end integration and collaborative optimization of the HEM supply chain, the construction of manufacturing service chains and collaborative scheduling, value network modeling and evaluation, and value network prediction and dynamic evolution. In these areas, the results of endto-end integration and collaborative optimization provide a theoretical basis for the study of collaborative scheduling. These results are integrated and thus provide a solid research foundation and theoretical support for value network modeling and evaluation. Value network prediction and dynamic evolution can be studied further on the basis of these results. The main research questions are presented as follows.

- End-to-end integration and collaborative optimization for the HEM supply chain. Analyzing the characteristics of HEM supply chain agreements in the internet and big data environments is necessary. Through such analysis, efficient collaborative optimization methods for the HEM supply chain can be constructed, and the optimization problems of each node can be quickly and efficiently solved in the dimensions of time and quality. In this way, the benefit of the entire supply chain is maximized.

- Construction of manufacturing service chain and collaborative scheduling. Achieving this goal requires a theoretical research framework of collaborative optimization for HEM service chains that considers the emerging technologies under the internet and big data environments. Evaluation systems and service resource optimization configuration plans are also necessary for service chain construction. Finally, collaborative optimization schemes can be formed by combining the design of mechanisms and dynamic operations for manufacturers and service providers in HEM.

- Value network modeling and evaluation for HEM. Value network models should be initially built for HEM supply and service chains with consideration of their characteristics in the internet and big data environments. These value network models can then be used as basis to construct systematic and quantifiable dynamic value evaluation systems that consist of multiple objectives and levels.
- Prediction and dynamic evolution of value networks. Considering various uncertainties in value networks given the new characteristics of HEM value network nodes is necessary to achieve precise prediction and evaluation. With such consideration, the correlations between various factors and indicators can be analyzed, and the performance of value networks can be evaluated and forecasted.

\section{Task integration management of innova- tive development in HEIM}

HEM develops toward digitization, intelligence, networking, and service orientation given the breakthrough in the development of new-generation IT. The process of HE innovation development has also demonstrated new features of customized manufacturing, open-source needs assessment, networked tasks, and systemized integration and verification. In recent years, many studies on task requirement analysis and management of HE development; task decomposition and resource allocation; task network analysis and evaluation; and system integration, verification, and evaluation have been undertaken to support fundamental theories for the study of integration management for the innovative development of HEIM (Fig. 4).

5.1 Task requirement analysis and management for the innovative development of HEIM

The viable solution to acquiring the requirements of the innovative development of HEIM is to combine the requirements collected by traditional survey methods and the potential hidden needs of stakeholders. With this perspective, we review the following closely related key technologies.

Web data mining. The determined potential demand for the innovative development of HEM is further processed and refined on the basis of the collection and preprocessing of original web data, including automatic text abstraction, topic detection and tracking, and sentiment analysis. Automatic text abstraction refers to the process of computers automatically extracting content from the original text and accurately generating the core content of a document. Query-oriented single documents can be summarized using a deep auto-encoder to compute a feature space from a term-frequency input (Yousefi-Azar and Hamey, 2017). Topic detection and the tracking of cluster public opinion from the internet lead to the discovery of interesting topics, which may be continuously monitored. Semantic frame-based topic detection is achieved through highly automated, knowledge-supported frame generation and matching mechanisms, taking advantage of multiple knowledge sources and extracting discriminative patterns from documents (Chang et al., 


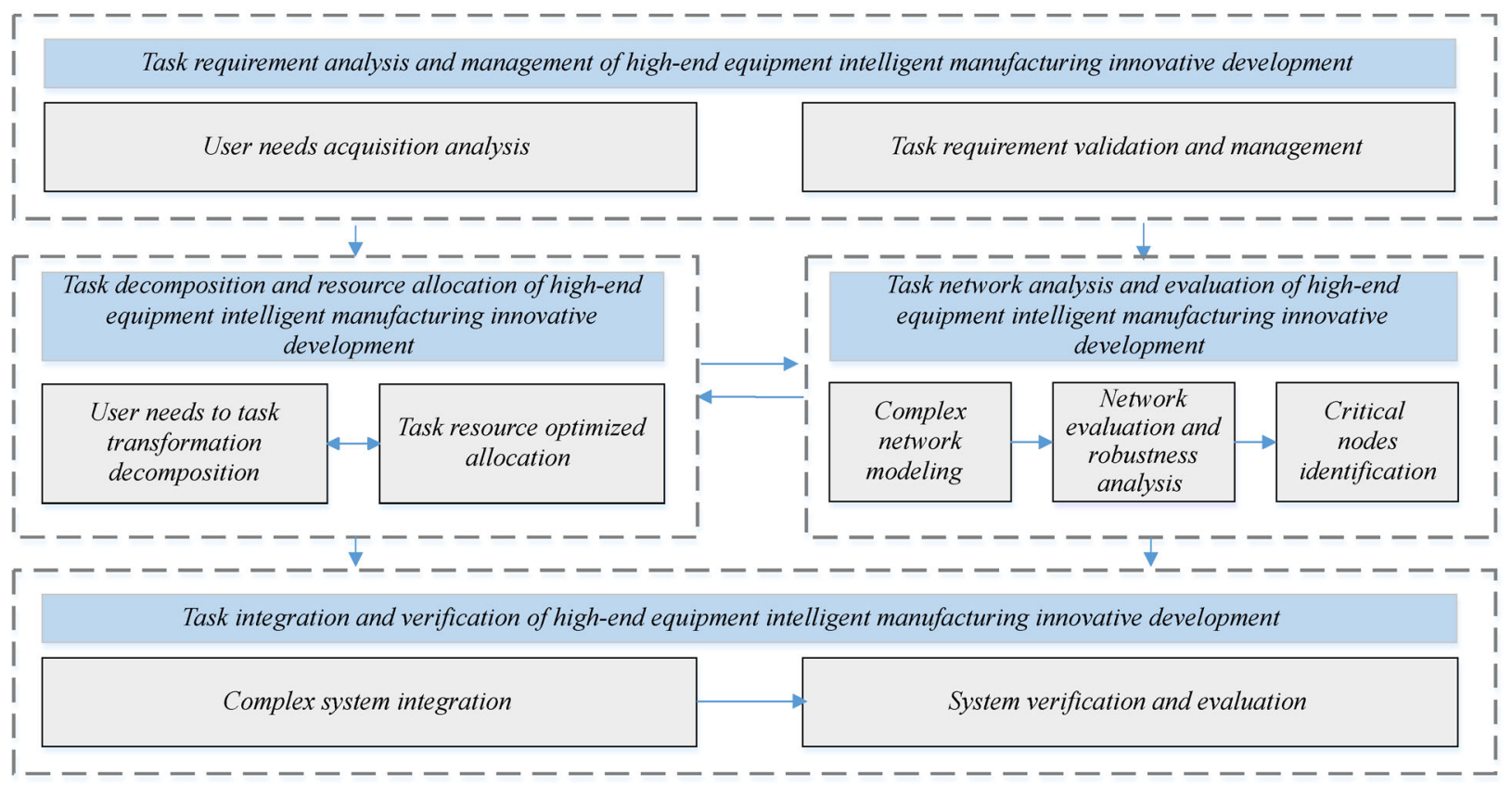

Fig. 4 Key research issues in task integration management for the innovative development of HEIM

2017). Topic tracking systems are improved by adopting keyword weights and incremental learning. Changes in topic structure and key topics can be tracked by a selflearning finite mixture model ( $\mathrm{Li}$ et al., 2015). Text sentiment analysis or sentiment mining refers to the process of detecting, analyzing, and mining subjective texts that embody the preferences, opinions, and emotions of users. Recently, a divide-and-conquer approach that applies a neural network to classify the sentiment of sentences has been proposed (Chen et al., 2017).

Knowledge graph construction. Raw data obtained from the internet have unstructured characteristics, thereby posing great challenges in discovering requirements from original data. Establishing intelligent semantic retrieval networks provides a solution to requirement analysis (Schouten and Frasincar et al., 2016). The semantic network is a network of data, including knowledge graphs, that provides users with a query environment and returns data that are processed and inferred in a graphical manner. The overall construction process is divided into three stages, namely, information extraction, knowledge fusion, and knowledge processing. The first step of information extraction is the extraction of entities and the extension of the entity corpus iteratively through an open-domain unsupervised learning algorithm (Yu et al., 2016). After the extraction of entities, a series of discretely named entities are obtained. However, extracting the relationship between these entities, that is, relationship extraction, is also necessary. Relationships can be extracted by methods based on self-supervised learning and conditional random fields (Zhang et al., 2016). Ambiguity, redundancy, and error can be eliminated through knowledge fusion such as entity linking and knowledge mergers. Entity linking, which mainly includes entity disambiguation and coreference resolution, refers to the operation of associating the entity object extracted from the text to the corresponding entity object in the knowledge base. A general framework has been presented to link named entities in web free text with a heterogeneous information network (Shen et al., 2018). Finally, when a knowledge graph is constructed, the knowledge input can be obtained from a third-party knowledge base or structured data for further knowledge processing.

In general, the technology for web data mining and knowledge construction has been relatively well developed, but research on task requirement analysis and management for the innovative development of HEM is limited because these studies started later. Therefore, studying the scientific issues in the requirement analysis of the innovative development of HEM is a key task for the future.

5.2 Task decomposition and resource allocation for the innovative development of HEIM

The innovative development of HEIM is a complex system engineering task that integrates fields, industries, regions, and disciplines. The first task of innovative development is to transform individualized user requirements into system design and development task requirements. In the innovative development of HEIM, coordinating the allocation of resources, such as people, finances, and materials, for each development unit and team and optimizing the allocation of resources for tasks are 
necessary.

After the requirement analysis of innovative development, the results of the requirement analysis and task decomposition should be translated into the corresponding platform or system to facilitate their implementation. Zheng et al.(2015) translated the requirements of satellite systems into tasks to improve the scheduling and planning of on-orbit satellite missions. Product collaborative design in distributed heterogeneous environments is increasingly important given the continuous expansion of HEIM enterprises. Further studying the mapping relationship between requirements and functions with collaborative designs is necessary (Liu et al., 2014). In the activity-based methodology delivered from the US Department of Defense Architecture Framework, each view product is developed, and the key relationships are correlated (Lee and Park, 2015). The optimization of resource allocation is a main content of the task optimization for innovative development in HEIM. The resource-occupying priority rules in portfolio projects are related to influencing factors such as network density, iterative intensity, and resource conflict degree (Browning and Yassine, 2016). With regard to the optimization of resource allocation, the literature uses multi-objective evolutionary algorithms (Lin and Chiu, 2018). During the implementation of HE development tasks, the task progress and resource status change dynamically. Further studying the development of task dynamic resource allocation is necessary (Bertsimas et al., 2017).

In general, the current literature already includes some research on task decomposition and resource optimization. However, few studies have focused on task decomposition structure and resource allocation for the innovative development of HEIM. In terms of the task decomposition structure, an in-depth study based on the multi-view architecture description method should be conducted. In terms of resource allocation, the resources required for each sub-task are generally assumed to be fixed, and the resource allocation in the sub-task should be investigated further under the condition in which the amount of resources is variable. In addition, the dynamic resource allocation of development tasks requires extensive research. Therefore, carrying out in-depth analysis and research on task decomposition and resource allocation optimization is necessary for the innovative development of HEIM.

5.3 Task network analysis and evaluation of HEIM innovative development

The relationship between the tasks of HE development involves multiply attributes and is hierarchical, dynamic, and networked; thus, traditional modeling methods are not applicable. At the same time, HE development tasks are complex and are challenged by a variety of risk factors. Hence, ensuring the robust scheduling of developing tasks is critically important. The existing research on the application of big data and the IoT in engineering project management mainly focuses on network modeling, robustness analysis, and critical node identification.

Complex network modeling. Industrial big data are a key element in the project management for the innovative development of HE. The rapid development and application of IT, such as the IoT and big data widely used in project management in many industries (Whyte et al., 2016), have caused revolutionary changes to task network analysis and the evaluation of HE development projects. During project management for the innovative development of HE, traditional methods such as critical path, Petri network, and hierarchical task network are limited due to over-simplified model abstraction, low computational power, and lack of capability to model complex interactions. Complex networks, as an abstraction of complex system structure and mechanism, provide an innovative modeling approach for large-scale engineering project management. Task organization networks and information flow optimization are analyzed by applying a design structure matrix (DSM) and dynamic network analysis methods in complex project design and implementation (Parraguez et al., 2016). With interdependent networks as an effective modeling framework to solve project management problems, a generalized percolation model has been proposed (Yuan et al., 2017), and the impact of interdependence on the cascading effect in interdependent networks has been analyzed using analytic solutions and simulations (Buldyrev et al., 2010). In addition, the robustness of interdependent networks has been studied, and several effective strategies have been proposed to control cascading effect propagation (Hong et al., 2016).

Network evaluation and robustness analysis. The current literature reviews focus on the selection of metrics to measure the task completion level for network robustness analysis and the capabilities to evaluate the stability of task networks. Many measurements, such as the multi-metric approach, a system of system frameworks, and the so-called end-to-end connectivity, as well as an "average reliability," have been proposed to evaluate the reliability and connectivity of networks. Network robustness has been evaluated by the degree of difficulty, for example, when considering the network being destroyed in the case of a network outage (Aouchiche and Hansen, 2013). A greedy model with small world properties has been developed to improve the robustness of heterogeneous IoT (Qiu et al., 2016).

Critical node identification algorithms. The identification of critical nodes in task networks during project management can be categorized depending on whether global information is used. When global information is used, a variety of network parameters, such as closeness centrality, betweenness centrality (Brandes et al., 2016), and $\mathrm{k}$-core score, may be adopted to measure the importance of nodes. The shortcoming of these measure- 
ments is that the calculation requires knowing the entire structure of the target network, and the calculation of certain matrices has high time complexity. Therefore, the identification of critical nodes with limited information provides an alternative when these techniques are not practical. These measurements include local centrality, PageRank score, and LeaderRank score. The algorithms for calculating these scores are comparatively simple and have low accuracy given that only local information is used. A new measure, efficiency centrality (EffC), has been proposed to identify critical nodes (Wang et al., 2017). This approach identifies critical nodes by removing each node while considering the changes in the entire network efficiency after removal.

In general, we have identified substantial literature reviews on the application of the IoT and big data in project management, as well as many studies focusing on applying a network approach to facilitate the management of complex and large-scale projects. However, in the era of new-generation IT, network modeling approaches and robustness analysis are rarely used to incorporate the characteristics of HE development tasks; thus, their application should be studied in the future.

\subsection{Task integration and verification for the innovative} development of HEIM

System integration involves the effective combination of components or subsystems to provide system functionality and satisfy system requirements (Hirshorn, 2017). In the development of complex systems such as those for equipment manufacturing, system integration faces additional challenges, including increasing system size and the need for system adaptability (Neches and Madni, 2013). With the emergence of IT such as the internet, the elements of system integration have become increasingly extensive, and the hierarchical and dynamic features of system integration have become prominent. As a result of the diversified elements of system integration, the verification and evaluation methods in the integration process have become one of the key topics in related fields.

Complex system integration. Integrated management, as the core content of project management, has received considerable attention since the 1980s (Stuckenbruck, 1997). The impact of different integration mechanisms in $\mathrm{R} \& \mathrm{D}$ projects on project performance has thus been studied (Sicotte and Langley, 2000). With such research, integrated content and elements have expanded quickly, thereby covering information, knowledge, data, resources, departments, and personnel. In addition, the integration of knowledge has become particularly interesting to researchers. Madni and Sievers (2014) pointed out that system integration has become the core content of systems engineering, especially in the fields of national defense and aeronautics. In the context of such growing complexity, the development and production cycle of projects are extended along with the expansion of project scale, and the elements in different phases of the project life cycle must be integrated. Eslami and Lakemond (2016) studied internal integration methods for complex products and found complex network structures and diverse relationships among HE innovative development tasks, as well as overlaps, crossovers, and iterations. For the design and development of complex products such as HE, task networks can be represented by DSM, which plays an important role in system integration and testing analysis, internal organization integration, and process integration and presents a wide range of application prospects (Browning, 2016).

System verification and evaluation. Verification and evaluation are important in the task management of largescale projects. The earliest verification of project management relied on the experience of project administrators and then on the approach of document-based systems engineering. With the extensive practice of model-based system engineering, model-driven validation and evaluation are increasingly favored by large-scale manufacturing companies. Model-driven executable models, discrete event system simulation, and simulations based on commercial software are the current mainstream methods.

An integrated system could be problematic due to the complexity of HE innovative development tasks. Thus, establishing an appropriate framework for task integration systems is important. The proposed Bayesian method integrates model validation and calibration activities into a single entity and quantifies the uncertainty of different types of engineering systems (Sankararaman and Mahadevan, 2015). Evaluating the effectiveness of HE using a single method is difficult given the unique complexity, uncertainty, emergence, multi-interest, and other characteristics of innovative development tasks. As a result, a hybrid approach based on executable models, analytics, expert knowledge, and other methods is important for the task evaluation of HE.

In general, the cross-regional and cross-trade characteristics of HEM are distinct in the new information era. Existing system integration methods cannot cope with the convergence and integration of HE innovative development task networks. Most traditional offline system integration processes cannot efficiently use the data and information dynamically generated during the integration of HE innovative development task networks. Moreover, few theories and methods for the verification and evaluation of dynamic behavior have overlooked knowledge, information, resources, organization, and technology in the integration process.

\subsection{Challenges and research opportunities}

In summary, although existing studies have carried out extensive related work in the areas of demand analysis and management, task decomposition and resource allocation, 
network modeling and analysis, and system integration verification, few systematic studies on the management of HEM exist. Moreover, despite the preliminary achievements of the application of architectural frameworks and "V" models, which are advocated by professional organizations such as NASA, Boeing, and INCOSE, related practice under new-generation IT is still in its infancy. Therefore, in light of China's national conditions and development requirements in facing the internet and big data environments, comprehensive work still needs to be performed to systematically carry out the research on the integrated management and innovative development of HEIM. In this regard, user needs analysis, task decomposition and resource configuration, task network analysis, and task integration and verification have generated research attention.

\section{Operation optimization of smart factories for HEIM}

The new technology revolution represented by the internet and big data greatly affects the operation optimization and management of smart factories for HEIM. New challenges include complicated production systems and their operation, intensive use of innovative knowledge, dynamic and uncertain manufacturing processes, and evident manufacturing service value orientation. In response to these challenges, much research has been carried out in the following aspects: Smart factory modeling, knowledge discovery and management, adaptive scheduling and optimization, operation mode, and management innovation. These studies have laid a theoretical and methodological basis for research on the operation optimization of smart factories. In the following sections, we discuss recent developments in these areas. The relationships are shown in Fig. 5.

\subsection{Modeling theory and smart factory method}

A national strategy of the Chinese government, "China Manufacturing 2025," suggests that smart factories should be considered an important vehicle to realize intelligent manufacturing. Recent research on the analysis and modeling of smart factories focuses mainly on four aspects.

Building a smart factory model with the industrial internet. $\mathrm{Li}$ et al. (2017) discussed a 5C architecture composed of connection, conversion, cyber, cognition, and configuration layers. With real-time data acquisition from a physical space and feedback from cyber layers, the intelligent decision making of factories can be implemented by data fusion and cloud computing. Taratukhin and Yadgarova (2016) proposed an industrial internet-based decentralized model benefited by a multi-agent and service-oriented architecture.

Building a smart factory model with a cyber-physical system (CPS). Shin et al. (2018) designed a dynamic reconfigurable factory CPS, which is capable of selfmanagement, on the basis of support vector machines (SVMs). Adamson et al. (2017) constructed an eventdriven manufacturing model on the basis of distributed collaborative CPSs; this model achieves distributed control and the adaptive matching of manufacturing resources and tasks.

Building a smart factory model with cloud manufacturing. Xie et al. (2017) proposed a linked semantic model. Distributed and isolated manufacturing information resource services, processed by semantic matching algorithms, are integrated and then shared in the manufacturing cloud environment. Lin et al. (2017) proposed a global optimization structure for cloud manufacturing. The multicentric model achieves a balance between manufacturing resources and capabilities.

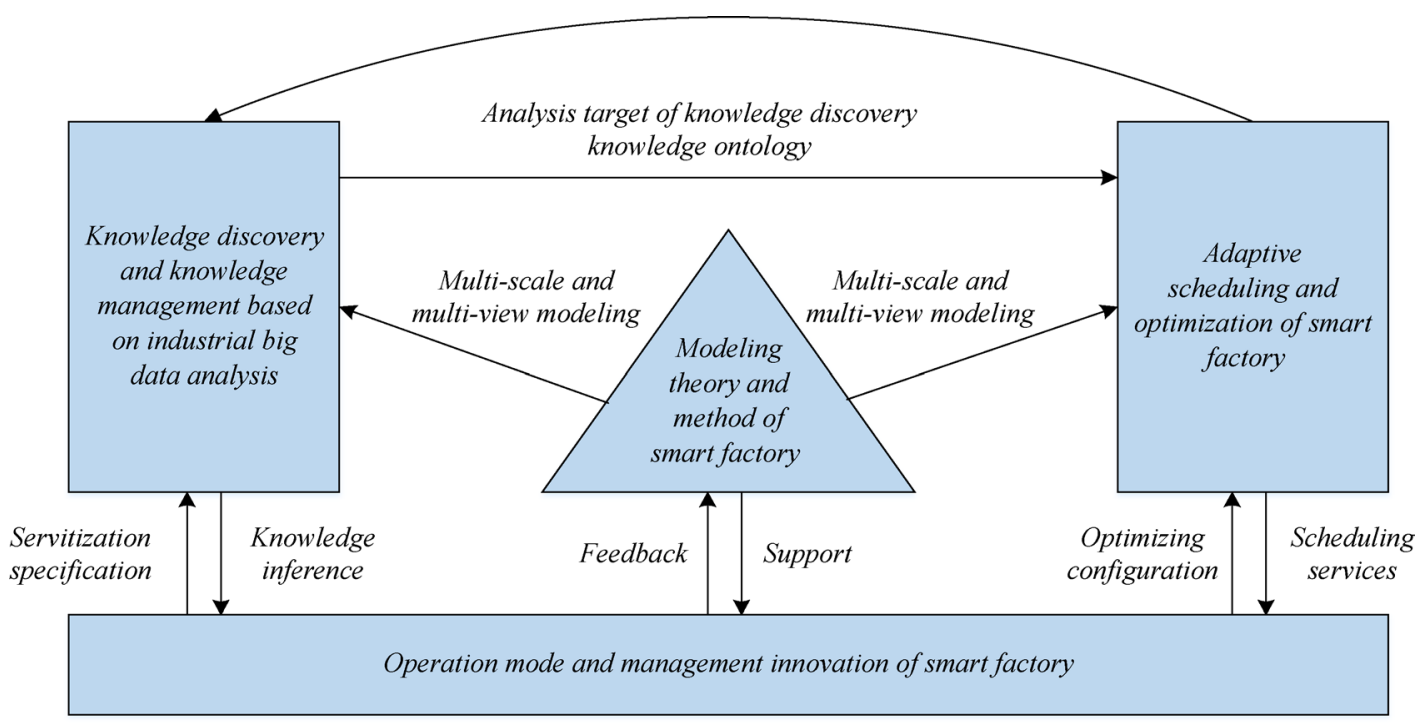

Fig. 5 Key research issues in operation optimization of smart factories for HEIM 
Building a smart factory model with a fractal enterprise. Considering the self-similarity of structures in factories, Pirani et al. (2016) introduced fractal theory into the modeling of smart factories as a scalable tool to promote production efficiency. Bider et al. (2017) put forward a fractal enterprise model. The fractal factory model created by the proposed method obtains clear relationships among all parts of the enterprise.

Therefore, current research focuses on applying various new IT in smart factory modeling theories and methods to address the challenges of decentralized resources and complex structures. However, the results show that the deep integration of these types of technologies is necessary.

6.2 Knowledge discovery and management methods based on industrial big data analysis

With the gradual penetration of big data technology into industrial fields, extracting potential knowledge from big data in smart factories has become the key technology for manufacturing management. This process also plays an important role in production optimization, fault diagnosis, and maintenance prediction.

Knowledge discovery. Xu and Hua (2017) summarized the current status and research strategies of industrial big data analysis in smart factories and proposed a knowledge discovery method that is based on deep learning for equipment fault diagnosis. Luca (2015) proposed a modified predictive knowledge model to improve the capability to handle large-scale process data and enhance the reliability of production processes. Sun et al. (2016) proposed a new type of deep neural network to implement unsupervised learning for feature extraction. Maier et al. (2017) proposed a machine learning-based fault correlation and diagnosis method. Through offline analysis of fault data, fault-related knowledge was obtained, and workshop scheduling was optimized.

Knowledge modeling and management for smart factories. Chen et al. (2015) proposed a multi-source knowledge combination scheme for personal customization and adopted an ontology-based complementary knowledge combination mechanism to construct a product knowledge ontology. Zhang et al. (2016) studied a collaborative modeling method of performance prototypes for aerospace products based on ontology. Dai et al. (2015) proposed a process-oriented ontology knowledge network to solve reliability modeling and verification problems in manufacturing industries. Zhang et al. (2014) proposed a knowledge management method for heterogeneous product design/process knowledge.

Evidently, knowledge discovery for smart factories must fully utilize big data and machine learning. People, devices, and data of smart factories can be effectively organized on the basis of knowledge. In the aspect of knowledge management, ontology-based knowledge modeling methods play an important role in the implementation of cross-domain integration and knowledge reuse.

\subsection{Adaptive scheduling and optimization of smart factories} for HEIM

Smart factories run in highly uncertain, random, and unpredictable manufacturing environments. An efficient production scheduling system for smart factories must improve its capability to respond rapidly to dynamic production processes. Related research includes the following aspects.

Dynamic scheduling approach of manufacturing systems. The three types of scheduling approach under uncertainties include proactive scheduling (Xiong et al., 2013), reactive scheduling (Priore et al., 2014), and hybrid scheduling (Nugraheni et al., 2016). Xiong et al. (2013) studied robust scheduling with random machine breakdowns to enhance their adjustable abilities based on predictions. Priore et al. (2014) presented a machine learning-based dynamic scheduling approach that adjusts dispatch rules in real time. Rahmani and Heydari (2014) proposed a proactive-reactive scheduling method while considering unexpected arrivals of new jobs and uncertain processing times.

Intelligent optimization algorithm for manufacturing systems. The scheduling optimization problem of manufacturing is NP hard and is even more difficult in uncertain environments. Intelligence-based methods are generally adopted to obtain approximate optimal solutions under a reasonable computational complexity (Laalaoui and Bouguila, 2014). Available intelligent algorithms for scheduling include genetic algorithm, tabu search, ant colony optimization, simulated annealing, particle swarm optimization (PSO), and various hybrid methods (Qiu and Lau, 2014).

Integrated scheduling structure of manufacturing systems. A systematic scheduling solution with a reasonable structure has been the focus of researchers in recent years given that every scheduling model or method often struggles to deal with dynamic scheduling of complex manufacturing. GóMez-Gasquet et al. (2011) studied a framework for improving planning-scheduling collaboration and developed software set in an actual industrial production environment. Tsai and Huang (2007) constructed a scheduling and rescheduling system that integrates a real-time scheduler and rescheduling mechanism on a simulation platform. Li and Qiao (2012) discussed three-level scheduling architecture (production planning, production dispatching, and rescheduling) and two-level scheduling architecture (production planning and real-time scheduling).

As indicated by the abovementioned research on 
scheduling approach, algorithms, and structures, prospects for future research in this field could include closed-loop optimal controls for smart factories, industrial big datadriven scheduling algorithms, and multiple-level interactive adaptive scheduling structures.

6.4 Operation mode and management innovation of smart factories for HEIM

As the typical carrier of smart manufacturing, smart factories and their management innovation attract the interest of many researchers, who mainly focus on the following aspects.

Service-oriented manufacturing (SoM) mode. In SoM mode, the full life cycle value creation is realized through the efficient collaboration of productive service, manufacturing service, and customer participation. Mendes et al. (2012) proposed an integration method for the design, analysis, validation, simulation, and process execution in SoM systems. Lee et al. (2014) introduced manufacturing service innovation and smart analytics for industry 4.0 in big data environment. Guo (2015) put forward new manufacturing values of "customer-, service-, and customer-centric" instead of the old ideas of "producer-, product-, and data-centric."

Data and model-driven smart production. Fink et al. (2014) studied the model-based decision support problem in manufacturing and service networks. Chen (2015) proposed a manufacturing servitization engineering methodology for the creation of manufacturing services and service systems. Quintanilla et al. (2016) presented a design methodology for product-driven applications of customizable product-process specifications based on manufacturing services.

Collaborative service configuration, management, and optimization methods. Zhang et al. (2013) proposed a methodology that combines social network and collaborative filtering techniques for personalized manufacturing service recommendations. Guo et al. (2012) proposed the concept of resource service composition (RSC) and studied the measurement method of RSC flexibility in SoM systems. Zhang et al. (2016) proposed a novel method for multi-criteria decision making and the evaluation of manufacturing services based on collaborative filtering and interval-valued intuitionistic fuzzy theory.

In addition to SoM mode, data and model-driven production, and service collaborative management, future research can explore service configuration models, servicedriven smart production and its operation framework, and a collaborative optimization method for complex business processes in smart factories.

\subsection{Challenges and research opportunities}

In the internet and big data era, new technologies provide challenges and opportunities for smart factories and their operation management. For operation optimization issues in smart factories, the focus of innovation should be on enhancing self-learning, self-organization, and selfadaptation capabilities. Related research is still in progress, and possible future research directions are identified as follows.

- Smart factory modeling theory and method for advanced equipment manufacturing. With the background of a cyber-physics system and the industrial internet, the future research in this field should aim to realize the adaptive organization of distributed manufacturing resources, form flexible factory organizations combined with fractal theory, and provide an intelligent cloud service model driven by industrial data and customized requirements.

- Knowledge discovery and knowledge management methods based on industrial big data analysis. The focus of future research of knowledge discovery and management lies in knowledge ontology modeling and machine learning-based algorithms to deal with crossdomain, multi-source, heterogeneous, and dynamic industrial big data. Such focus will help realize the extraction, reasoning, and application of knowledge in manufacturing operation management.

- Adaptive scheduling and optimization of smart factories for HEIM. With an adaptive scheduling structure for smart factories, the industrial, big data-driven intelligent scheduling algorithm and closed-loop optimization control methods should be studied to provide a theoretical and technological foundation for the production optimization of smart factories for HEIM.

- Operation mode and management innovation of smart factories for HEIM. Future research work should build the architecture of operation mode and management method for smart factories from the following two aspects: i) data and service-driven operations and organization modes of smart factories and ii) collaborative service configuration, management, and optimization methods of smart factories.

\section{Quality and reliability management for HEIM}

High-tech equipment usually has complicated structures, requires large investments, and fulfills important tasks. It has a long service life with high reliability requirements. High-tech equipment is manufactured by customization in small batches and involves multiple research units and disciplines. Failure data are often limited or absent due to the high reliability of high-tech equipment, resulting in difficulties in reliability and quality management. Given that many research units and suppliers are involved in the development of high-tech equipment, ensuring adherence to the requirements of reliability and quality control presents challenges for the general unit and various 
research units involved. High-tech equipment produces massive amounts of data related to quality and reliability in the development, test, production, and usage stages of its life cycle. In the environment of the industrial internet and new generation of IT, a large amount of quality and reliability data can also be collected at different stages from various departments and levels of research units, e.g., monitoring data collected in the manufacturing process and usage. All these findings motivate the research into datadriven based quality and reliability management for hightech equipment intelligent manufacturing.

In the environment of the industrial internet, researchers are making full use of big data from different stages in the life cycles of different equipment and various enterprises and departments. Breakthroughs are made in data-driven quality control for high-tech equipment, and big data are based on high-tech equipment life predictions and prognostics health management. These research practices provide technical support to improve the quality and reliability management of high-tech equipment.

Figure 6 shows the relationships between the main research topics in quality and reliability management research for HEIM.

7.1 Big data-based quality control technology of high-tech equipment intelligent manufacturing

Statistical process control (SPC) technology is the most commonly used process quality control tool. However, for complex manufacturing processes (such as highdimensional multivariate processes with multiple inputs and outputs), SPC can neither effectively analyze complex multidimensional information or quantify process status and visualization nor can it efficiently identify process failure sources. Process quality control methods have evolved from SPC to statistical process adjustment through statistical process diagnosis (Castillo, 2006). The intelligent learning technologies widely used in manufacturing process quality control realize intelligent process quality control and automation, such as the automation of data acquisition and process monitoring and diagnosis, process knowledge extraction, and process adjustments. Despite these advantages, the integration of artificial learning technologies with SPC is still necessary to achieve efficient intelligent process quality control. Hence, the integrations and applications of SPC and artificial intelligence attract considerable research attention.

Artificial intelligence algorithms, such as artificial neural networks (ANNs) (Venkatesan et al., 2009), SVMs (Chinnam, 2002), and fuzzy algorithms (Wang and Chen, 2002), have been successfully applied to the quality control of manufacturing processes. ANN is one of the most attractive tools in the study of the application of artificial intelligence in quality control. Characterized by nonlinearity, parallel processing, noise tolerance, and good learning properties, ANNs present good prospects in the field of quality control, and they have been applied in monitoring and diagnosis for the application of three typical manufacturing processes: Single variable discrete processes, auto-correlated processes, and multivariate processes (Cheng and Cheng, 2011). However, the applications of neural networks entirely depend on user experience due to the lack of strict theoretical systems. Although Hornik et al. (1989) have proven that feedforward networks with one nonlinear hidden layer can approximate any complex nonlinear function with any precision, finding a suitable neural network configuration is an NP problem (Judd, 1987).

For a complex manufacturing or chemical industrial process, principal component analysis (PCA) (Lin et al.,

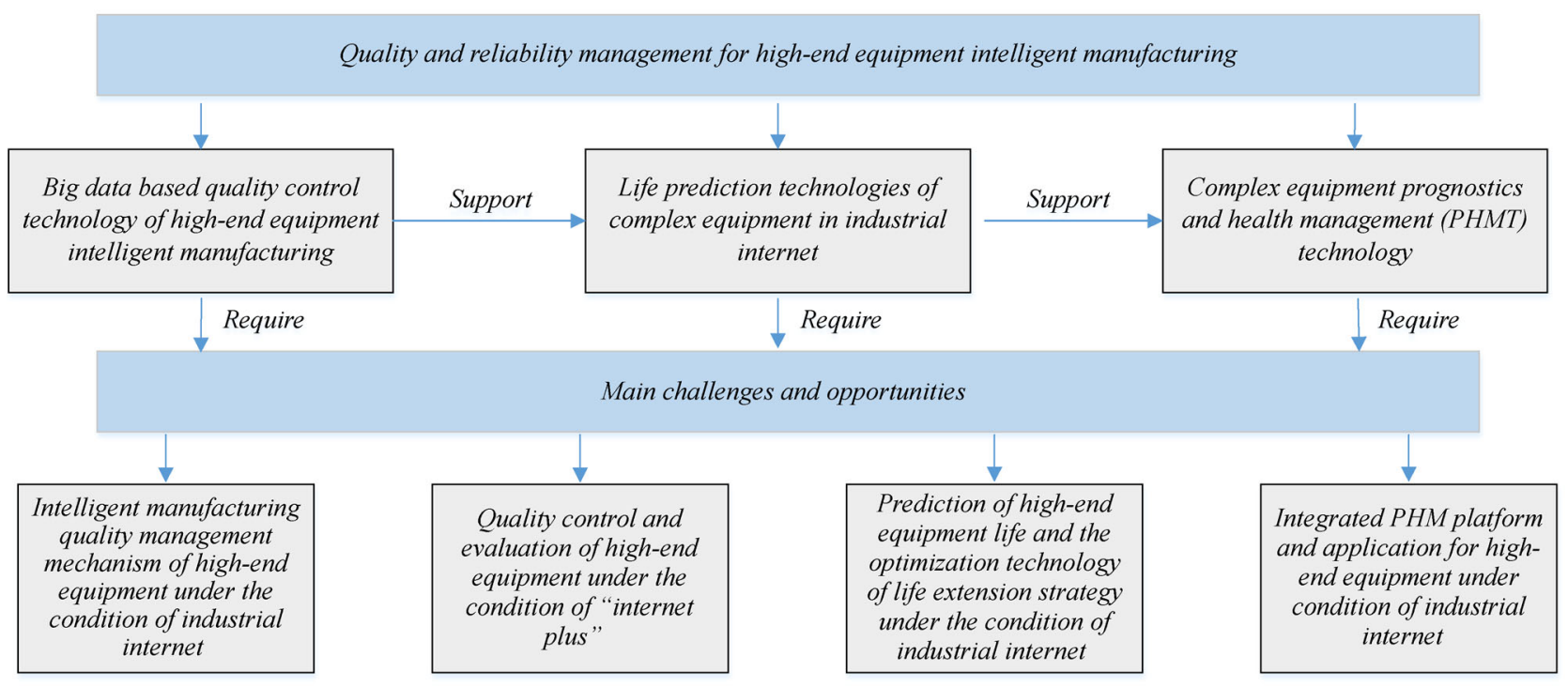

Fig. 6 Key research issues in quality and reliability management research for HEIM 
2000) is often required to compress or project interrelated process variables into a few principal components to monitor processes in low dimensional spaces. Statistical process monitoring methods, such as PCA, are linear modeling methods, whereas many manufacturing processes are nonlinear in nature. In these cases, process data are analyzed by nonlinear analysis methods, such as ANNs, the main element curve method (Zhang et al., 1997), or the kernel learning method (Lin et al., 2000). Yang et al. (2012) proposed independent component analysis to separate multiple signals in process control and extract independent components hidden in stochastic variables.

With the rapid development of computer and communication technologies, as well as the vast amounts of data produced in complex equipment manufacturing processes, quality control methods have evolved from manual data acquisition and analysis to the automation and intellectualization of all stages of the integrated quality system, such as automatic data acquisition, intelligent monitoring, intelligent fault diagnosis processes, intelligent knowledge extraction, and process adjustment. Moreover, the intelligent manufacturing of high-tech equipment has been used in various production modes with small batches. Therefore, under this mode of production, the implementation of intelligent and automatic process monitoring and abnormal diagnosis and adjustments will continue to be key research directions in the future.

7.2 Life prediction technologies of complex equipment in the industrial internet

Life prediction, frequently quoted as residual life prediction or remaining useful life prediction, is critical for complex equipment. Over the years, the residual life of complex equipment sets, such as aerospace, marine, and weapon equipment sets, has been analyzed from single components to the system level. Comprehensive and systematic investigations have been conducted according to various materials, theories, and experiments, yielding a variety of residual life prediction methods. Corresponding residual life prediction methods are varied due to the different characteristics of complex equipment. However, most of the methods use historical data to verify the chosen life prediction model. The monitoring data are then applied to predict residual life, perform parameter calibration, and update data to achieve online condition monitoring and residual life prediction. According to the use of monitoring data, the methods of residual life prediction can be classified into three types: Physics of failure (PoF)-based methods, data-driven methods, and methods based on the fusion of the two (Pecht, 2009).

PoF-based methods. These methods establish residual life prediction models on the basis of failure mechanisms of different physical characteristics of systems in the process of degradation (creep, fatigue, corrosion, and wear). Zhu et al. (2016) studied the fatigue life prediction of aircraft engine turbine disks on the basis of PoF analysis. $\mathrm{Gu}$ et al. (2007) adopted a finite element model and vibration fatigue failure model by means of PoF analysis and investigated the prediction method for the residual life of electronic products under vibration load. Such methods truly reflect equipment failure, but the modeling and analysis process is usually complicated due to the intricate nature and varied performance of equipment in different environments, thus requiring specific modeling by associated failure mechanisms.

Data-driven methods. These methods mainly include the prediction methods based on artificial intelligence and those based on probability statistics. Prediction methods based on artificial intelligence include neural networks (Qian and Yan, 2015), SVMs (Moura et al., 2011), proportional hazards model (Wu and Ryan, 2011), hidden Markov models (Tobon-Mejia et al., 2012), and stochastic filtering models, particularly the Kalman filtering method (Baraldi et al., 2012) and the particle filter method (Orchard et al., 2005). These methods do not need an assumption of lifetime distribution; they adopt training models built from training information to fuse new observation data to conduct life prediction. However, the excellent performance of these methods requires a large amount of failure data, which are unavailable for highly reliable equipment. Unlike interval estimation, which can describe the uncertainty of residual life prediction, prediction methods based on artificial intelligence generally obtain the results of point estimation. The other methods based on probability statistics, such as regression model (Caesarendra et al., 2011), the Wiener process (Wang et al., 2014), the gamma process (Wang et al., 2015), and Bayesian theory (Jia et al., 2017), establish degradation models on the basis of degradation data to derive the probability distribution of residual life under the framework of probability theory. Thus, the methods not only obtain the mean residual life but also consider the uncertainty of the external environment and internal products, indicating their wide application in the field of mechanical and electrical engineering. Wang et al. (2014) studied the skewed normal random effects of a univariate nonlinear Wiener degradation process model corresponding to nonlinear degradation, along with the uncertainty on the timeline and the differences between products, to predict residual life. Wang et al. (2015) also investigated the degradation of bivariate non-stationary gamma degradation process modeling and residual life calculation methods. In the cases of multiple performance parameters of degradation, Wang et al. (2015) proposed a multivariate Wiener process to describe the degradation and calculate the degradation model parameters on the basis of the EM algorithm. Zhang et al. (2015) introduced a multi-kernel relevance vector machine (MKRVM) method based on a PSO algorithm to establish multiple monitoring parameters and the relationship between key performance parameters. 
A hybrid MMKRVM method that can facilitate the collection of lithium batteries with an additional indirect health index is presented to predict battery capacity (Zhang et al., 2017). Given that multi-source information, such as performance data, lifetime data, and similar product data, can be collected in the life cycle, methods based on multisource information can be used to predict the residual life of equipment and solve the small sample of life prediction of highly reliable equipment. Liu et al. (2017) fused degradation and lifetime data using Bayesian methods to predict the residual life of products. Han et al. (2014) presented the reliability data of similar products by Bayesian method fusion to obtain the interval estimation of the residual life of current products.

Life prediction methods based on the integration of PoF and data-driven methods. These methods combine PoF models with the results of data mining applications, along with available information fused by elaborately selected approaches, to predict residual life. An et al. (2015) summarized the selection approaches to combine data-driven methods with PoF-based methods. Zio and Di Maio (2012) studied the damage expansion mechanism using relevance vector machines combining data- and model-driven methods to predict the residual life of cracked components. Zhao et al. (2013) applied a finite element model to analyze the stress of gears, calculated the gear dynamic load using a dynamics model, used the Paris method for a crack propagation model, and applied a Bayesian method to fuse condition monitoring data and update the remaining life prediction.

Given that highly reliable products usually undergo a few failures, researchers studied the method using an accelerated test to advance product degradation or failure through the obtained data and to predict products' residual life under normal stress. According to product failure modes, accelerated tests can be divided into the accelerated life test (ALT) and accelerated degradation test (ADT). In ALT, the failure mode of the test object is mostly traumatic failure, and the data obtained from the test are the failure times. In ADT, the failure mode of the test object is degradation failure, and the test results include product performance degradation data. Thiraviam et al. (2009) indicated that the difficulties of ALT research mainly concentrate on the accelerated stress, acceleration model, failure mechanism, data acquisition, and environmental conditions, as well as the economics, statistics, and physics. The research on ADT mainly focuses on the statistical analysis and modeling of degenerate data, experiment design, and optimization research. $\mathrm{Lu}$ et al. (1996) proposed the use of the ADT method to solve the problem of the application of traditional test methods to highly reliable products to derive their life span; the authors also employed maximum likelihood estimation to handle accelerated degradation data. The simulation method was suggested to calculate the confidence intervals of reliability characteristics (Meeker et al., 1998).
Shocks during operation are not rare for industrial systems and often cause irreversible damage to system health. Given that shock durations are usually short, they can be considered instantaneous events compared with relatively long operation cycles. This phenomenon exhibits discontinuous non-differentiable characteristics in mathematical properties, which are difficult to characterize using traditional stochastic process models. Fan et al. (2000) considered that the impacts of random shocks on systems cause more damage than system degradation and then proposed the life prediction method. Li and Pham (2005) and Lin et al. (2015) recognized the impacts of shocks on the reliability of systems during degradation, divided the health status of a system into different discrete states, and further integrated impact damages to predict the residual life of systems.

The traditional method of predicting residual life through historical failure data are no longer applicable due to the increasing reliability of complex equipment. Related research mainly focuses on the big data collected in the life cycle of complex equipment, with performance degradation data attracting particular interest. The PoF, data-driven method, and the method combining the two are also applied to predict the residual life of equipment. However, most prediction models consider degradation as a relatively smooth continuous process, making them inapplicable when the equipment life cycle has more than two stages of degradation. In addition, a few life prediction methods regard the joint impact of discrete shocks and continuous degradation and that of incomplete maintenance on system reliability. The construction of residual life prediction models through the degradation of complex systems with different characteristics and various types of information has become a promising topic for the future.

\subsection{Complex equipment PHM technology}

Prognostic health management (PHM) through the inspection of component degradation, judgment of failure type, and prediction of failure time is the technology used to avoid system failure and maintain system health through preventive maintenance. PHM originated from NASA practices of integrated vehicle health management (IVHM) in the 1970s (Figueroa and Schmalzel, 2006). The proposed IVHM framework by NASA and Boeing provides 11 onboard management function modules to realize complete vehicle management. These modules not only enhance vehicle safety and mission success rate but also facilitate efficient operations. In the 21 st century, driven by the new generations of launch programs, a joint team composed of several centers has committed to the research on the health management of integrated systems. The US Navy initiated the research on open system architecture condition-based maintenance), which represents the future development direction of the integrated health management of complex systems (Kacprzynski 
et al., 2002). Boeing and Lockheed Martin integrated predictive and health management capabilities in their designs for the next generation of joint strike fighter aircraft (Millar, 2007).

Traditional PHM technology research began on single component systems in static working conditions, such as bearings with fixed rotational speeds and loads. Wu et al. (2012) and Zhou et al. (2012) respectively predicted the residual life of bearings working at a constant load and fixed temperature to realize maintenance decision. Given that most components and systems, such as car bearings or gears, are working under changing environmental conditions (Zhao et al., 2015), prediction models that can provide a satisfactory performance in varying working environments have been applied in many fields, such as network monitoring, network mining, and financial data management. The difficulties of PHM technology are twofold: i) analyzing mass data and establishing failure prediction models and ii) making maintenance decisions. Given that the data will drift during collection in varying environments and that the randomness of data are unpredictable, conducting corresponding studies is difficult due to the continuously changing relationships between the inputs and outputs of models (Elwell and Polikar, 2011). Some methods that can adapt to varying environments to update online have been developed to cope with the problem (Dries and Rückert, 2009). For example, algorithms with domain-adaptive kernels and semi-supervised learning can extract information from drift data while some active learning algorithms can reduce training costs by choosing the drift data of the most important information (Žliobaite et al., 2011). Another key to PHM implementation is the selection of appropriate decision-making targets for preventive maintenance. Feldman et al. (2009) proposed return on investment (ROI) as an economic performance indicator to evaluate PHM. Through ROI analysis, the best PHM solution can be selected, or the current maintenance strategy can be optimized.

The PHM technology of complex equipment is essentially based on the technology of state monitoring and preventive maintenance decisions, which is widely used in high-tech equipment, such as aircraft and highspeed trains. The application of PHM technology can increase reliability and availability, prolong life, ensure safety, and reduce the negative impacts of failure on environments (Kadry, 2013). The future challenges of PHM technology include the adaptation to modern complex systems, maximization of the health status of complex systems and the big data generated by maintenance, and development of efficient PHM technology. The efficiency of PHM technology lies in its capability to effectively handle complex systems in the detection, diagnosis, and prediction of different levels of uncertainty, provide maintenance decisions for different constraint conditions, and develop distributed and intelligent dynamic maintenance management systems to adapt to different levels of information exchange in complex systems, integration, and coordination.

\subsection{Challenges and research opportunities}

The rapid development of the industrial internet and IT profoundly affects the quality and reliability management of high-tech equipment manufacturing. The traditional mass production quality control methods, large samplebased reliability analytical methods, and life prediction methods are no longer suitable for the life cycle management of high-tech equipment. Therefore, the features of high-tech equipment intelligent manufacturing and the characteristics of life cycle data should be first considered. Next, quality management mechanisms for high-tech equipment intelligent manufacturing should be established. The quality control and evaluation methods for high-tech equipment should then be investigated on the basis of the life cycle of big data. High-tech equipment life prediction methods and life extension strategy optimization techniques should be developed, and the applications of PHM for high-tech equipment health management should be exercised. The main opportunities are as follows.

- Intelligent manufacturing quality management mechanism of high-tech equipment under the industrial internet environment. High-tech equipment is usually complex and involves various research units. Therefore, mechanisms for deriving quality and reliability requirements from equipment mission requirements, methods, and tools are limited, and a comprehensive demonstration of equipment performance and reliability indexes is insufficient. Different units for demonstration, development, and use are independently working without sufficient interactions. Effective standards, processes, and division of responsibilities to coordinate quality management are lacking. Under the condition of the industrial internet and intelligent manufacturing, each stage of equipment design, manufacture, supply, use, and service produces a large amount of data. Such data are scattered in different stages and units, which lack mechanisms and standards for life cycle data collection and sharing. Relevant mechanisms are required to improve the quality of the intelligent manufacturing of high-tech equipment.

- Quality control and evaluation of HE under the condition of "internet plus." By fusing modern manufacturing technology, artificial intelligence, statistics, SPC, and various intelligent algorithms, signal processing methods establish intelligent manufacturing process quality control systems to implement online intelligent monitoring and diagnosis and recovery process adjustment to handle the quality of high-tech equipment manufacturing. The integrated use of equipment life cycle data in quality assessment, including the establishment and optimization of an index system, an index weight system, and a quality assessment algorithm, should be studied to evaluate control efficiency. 
- Prediction of high-tech equipment life and the optimization technology of life extension strategies under the condition of the industrial internet. Under the condition of the industrial internet for high-tech equipment such as satellites, design data, test data, manufacturing data, field data, and data of similar products can be collected during their life cycle. Therefore, the fusion of multi-source data to develop life prediction methods and life extension strategy optimization methods is a promising research direction. This research identified the equipment reliability weakness, improved equipment designs, and provided optimal operation strategies, thereby prolonging the service life of equipment and guiding subsequent productions and launch plans. Thus, this research has important theoretical significance and application in the future.

- Integrated PHM platform and application for hightech equipment under the condition of the industrial internet. The research and demonstration application of a PHM integrated platform for aerospace equipment in the industrial internet environment is of considerable importance for the innovation and advancement of PHM theory and technology.

\section{Information management and intelligent decision making for HEIM}

The world has entered the information age. The rampant growth of a new generation of IT has infiltrated all aspects of the HEM industry, pushing it toward digitization, intellectualization, networking, and servitization. Such growth has profoundly affected the information management and decision-making modes of the HEM industry. In recent years, domestic and foreign scholars have conducted a body of research and exploration around sensor technology and artificial intelligence technology applications, information collection and processing for HEM, information service semantic integration and sharing for HEIM, and service-oriented collaborative service platforms for HEM. Scholars have designed innovative information systems and intelligent decision-making methods for HE manufacturers under the internet and big data environments. Complex intelligent decision support systems have also been constructed to provide enterprises with efficient decision support.

Figure 7 shows the relationships between the main research topics in information management and intelligent decision-making for HEIM.

8.1 Information management method for equipment manufacturing

The internet and big data are driving the transformation of information management modes, requiring enterprises to improve management abilities toward massive information. For the collection, transmission, and integration of data from different sources, Li et al. (2015) introduced the concepts of data portal and collaboration agency and proposed a data integration-oriented network integration

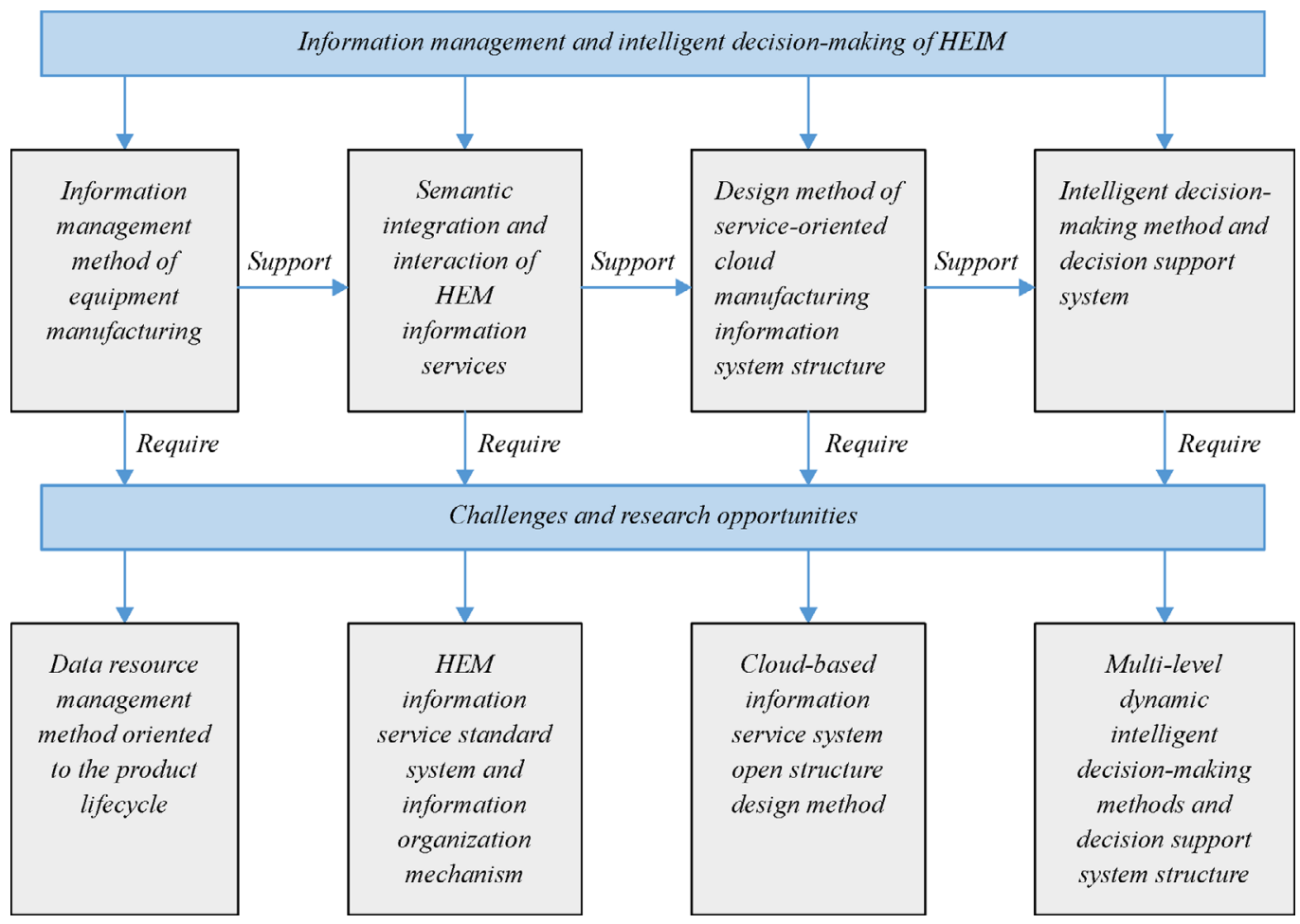

Fig. 7 Key research issues in information management and intelligent decision-making for HEIM 
information management method. Papakostas et al. (2016) designed a cloud computing-based hybrid assembly line preparation and design method and introduced a multiagent data integration framework and a data storage warehouse information management method with the participation of multiple stakeholders. For the management and utilization of massive data generated under the IoT environment, Abu-Elkheir et al. (2013) proposed an information management method that is based on basic design elements. Zhang et al. (2015) designed an information management method under abnormal manufacturing conditions. The designed system monitors production sites in real time, combining technologies of complex event processing, data cleaning, and data mining. To improve enterprises' production information management level for torque converters, Yang et al. (2017) presented a real-time data acquisition system framework that is based on OPC and database technologies according to the actual demands of MES in the digital assembly workshop. The framework can actually support the demands of real-time MES monitoring system and the production of business information processing.

Thus, in the information management research of equipment manufacturing processes, the existing literature mainly focuses on the collection, processing, and management of manufacturing process information. In future research work, establishing a manufacturing enterprise information management model under the internet and big data environment and designing an information management system for the entire life cycle of high-end manufacturing products are also necessary to achieve rapid and effective integration of internal and external data.

\subsection{Semantic integration and interaction of HEM informa-} tion services

The semantic construction of manufacturing information services is the consensus of researchers and developers around the world and is critical for the development of manufacturing servitization. Cai et al. (2011) proposed the concept of "manufacturing hub" based on semantic networks to illustrate and manage distributed manufacturing services. Xie et al. (2017) established a semantic model of semantic resource-based information resource service modeling. The model uses semantic links to realize automatic integration and distributed updating of resource service cloud. Jiao et al. (2017) proposed a service discovery method and service description based on ontology web service semantics due to a lack of semantic models in current service discovery. Khalfallah et al. (2016) presented and utilized the ontology model based on public standards to transform private information of enterprises into data integration standards for the aviation industry, which were shown to effectively increase the interoperability of product development in the aviation industry. For the existing mature manufacturing standards, scholars have conducted studies on the crossorganizational interactions of manufacturing information services. Wasmer et al. (2011) proposed an engineering change management standard for large equipment manufacturing on the basis of the exchange standards of product model data and the initialization graphics exchange specification. In the joint product development process, Houshmand and Valilai (2013) developed a new platform called "Distributed-LAYMOD," which facilitates product data exchange through the XML structure.

In terms of the semantic integration and interaction of manufacturing information services, the existing research focuses on the semantic integration and data sharing models of cloud manufacturing services and on the manufacturing sharing information standards. Future studies should concern the design of matching standard systems and interaction mechanisms for resource description and modeling methods of HEM service integration.

\subsection{Design method of service-oriented cloud manufacturing} information system structure

A cloud manufacturing information system enhances the efficiency of HEM enterprises by scientifically matching and monitoring the information, knowledge, and resources involved in manufacturing service parties. The structural design of a service-oriented information system is the key to a manufacturing service and resource matching process. Ameri and McArthur (2013) proposed a multi-agent information system structure design method in a "digital manufacturing market" in the cloud computing environment and designed an internal search and discovery algorithm based on semantic similarity to connect the providers and requestors of manufacturing services. Helo et al. (2014) presented a next-generation network MES system architecture design method to support information access by different types of enterprises. For the cloud manufacturing service modes of large equipment manufacturing enterprise alliances, Yang et al. (2014) designed a coalition resource coordination logic framework and a multi-level coordination mechanism. Modekurthy et al. (2015) introduced a cloud-based service broker system for cloud additive manufacturing that considers the preferences of consumers and the tradeoffs on service attributes, such as price, material, and accuracy, in the ranking process. Xu et al. (2015) proposed a design method for capacity information sharing systems on the basis of dynamic real-time device data to solve the problem of dynamic information and knowledge sharing in cloud manufacturing. This system comprises the ontology construction of manufacturing resources, a unified description framework, and the mapping relationship between real-time condition data and the model of manufacturing equipment capability ontology.

Thus, in the design of a service-oriented cloud manufacturing information system structure, the existing 
research concentrates on cloud manufacturing services, resource matching algorithms, and the distributed manufacturing unit coordination framework. Future research should build collaborative service platforms for HEM with high levels of compatibility and openness to integrate cross-domain and cross-subject cloud manufacturing resources.

8.4 Intelligent decision-making method and decision support system

Global manufacturing companies have imperious demands on production visualization and improvement of intelligent decision-making methods in the internet and big data contexts. Ahmad et al. (2017) proposed a knowledgebased intelligent decision system for conventional multiaxis machining. Zampou et al. (2014) constructed a general architecture for the manufacture of energy-aware systems to achieve energy management and provide intelligent decision support. Doukas et al. (2014) proposed an intelligent configuration method for global manufacturing networks for mass-customized production and designed an intelligent decision support system on the basis of an alternative multi-objective evaluation. The implementation of internet technology has promoted the wide utilization of electronic manufacturing technologies. Manupati et al. (2018) studied the World Wide Web collaborative model and proposed a web-based service system architecture to achieve the effective integration of distributed process planning and scheduling. Teran et al. (2014) introduced a decision support system for electronic manufacturing that integrates performance measurement and $\mathrm{Web}+$ service architecture. In response to the planning and scheduling decisions of large and heavy machinery enterprises, Ding et al. (2018) constructed an RFID-based social manufacturing system to enable the real-time monitoring and dispatch of production and transportation tasks among enterprises. Guo et al. (2015) proposed an RFID-based intelligent decision support system architecture to handle production monitoring and scheduling in a distributed manufacturing environment.

Thus, the current research on intelligent decisionmaking methods and decision support systems mainly focuses on the application of artificial intelligence and sensor technology at the enterprise workshop level. In the future, conducting in-depth research on collaborative optimization decision-making methods and decision support systems for the real-time manufacturing resources of $\mathrm{HE}$ in a new-generation IT environment is also necessary to achieve efficient collaborative decision making.

\subsection{Challenges and research opportunities}

HEM under the internet and big data environment involves extensive cooperation among suppliers, manufacturers, enterprise business departments, and users, constituting a complex big data environment. To give full credence to the value of resources for big data manufacturing and realize the optimization and cooperation of HEM service processes, future studies should explore the basic theoretical issues, such as the information processing of HEM under the internet and big data environment, crossplatform interactions of information systems, and collaborative decision making; data resource management methods for product life cycles; HEM information service standards and open structures; and intelligent decisionmaking methods and decision support systems.

- Data resource management method oriented to product life cycle. From the perspective of analyzing the characteristics of manufacturing big data, a semantic-based manufacturing life cycle data collaboration model, a data availability analysis theory model, and pre-processing and form conversion mechanisms for multi-source heterogeneous manufacturing data are constructed to achieve the full life cycle of manufacturing-oriented intelligence.

- HEM information service standard system and information organization mechanism. Starting from the HE information service, this study establishes a standard description structure of HE product information service and a semantic-based manufacturing service information organization method and constructs a product service information model on the basis of spatio-temporal relationship combinations from the perspective of spatiotemporal correlations.

- Open-structure design method for cloud-based information service systems. On the basis of the basic architecture of cloud computing, this study focuses on a cross-level information organization mechanism and system integration architecture and constructs an open information service system architecture using the value chain collaboration mechanism of HEM systems.

- Multi-level dynamic intelligent decision-making methods and decision support system structure. Starting from the network structure of manufacturing units, this study explores the environmental perception patterns and decision-making modes of manufacturing units distributed in multiple layers in a real-time manufacturing model and uses data visualization-related technology to construct the intelligent decision support system architecture for contextual visualization.

\section{Conclusions}

The industrial internet, cloud computing, big data, and artificial intelligence technologies constitute a major technical support for solving current engineering management problems and provide new historical opportunities for the research and development of engineering management theories for HEM. Under the new generation of IT environment, HEM is moving toward digitization, intellectualization, networking, and servitization. The novel 
theoretical and technical challenges in intelligent manufacturing engineering management include cross-lifecycle management, network collaboration management, task integration management of innovative developments, operation optimization of smart factories, quality and reliability management, information management, and intelligent decision making for HEIM.

Scientifically sound EM on HEIM can comprehensively integrate the multiple targets of natural, social, economic, scientific and technological, talent target, and cultural values from the level of strategic coordination. Providing attention and consideration to the management activities of intelligent manufacturing engineering from a high dimension is necessary to examine problems in the management of intelligent manufacturing engineering from a dialectical thinking level to drive the deep integration of EM philosophy and techniques, the coordination and unity of EM systems and details, the mutual promotion of EM standards and innovation, and the joint improvement of EM talent teams and regimes in the circulative progress of EM theory and practice.

Acknowledgements We appreciate the support and advice given by Professors Kewei Yang, Bo Guo, Li Zhang, Min Liu, Hao Zhang, Jian Wang, Xinbao Liu, and Minglun Ren. We are grateful for all the help we received from other researchers and students in our group, such as Drs. Lijie Wen, Jie Song, Xi Zhang, Xiaoyun Xu, Bingfeng Ge, Ping Jiang, Xin Lu, Yajie Dou, Xiang Zhao, Yunyan Xing, Xiang Jia, Jianfeng Lu, Yiru Dai, Yumin Ma, Qiang Zhang, Jun Pei, Xiaonong Lu, Zhanglin Peng, Jianguo XU, Ge Huang, Xilin Zhang, Yuren Wang, Mengsi Cai.

\section{References}

Abedjan Z, Golab L, Naumann F (2015). Profiling relational data: A survey. VLDB Journal, 24(4): 557-581

Abu-Elkheir M, Hayajneh M, Ali N A (2013). Data management for the internet of things: Design primitives and solution. Sensors (Basel), 13 (11): 15582-15612

Adamson G, Wang L, Moore P (2017). Feature-based control and information framework for adaptive and distributed manufacturing in cyber physical systems. Journal of Manufacturing Systems, 43: 305315

Ahmad R, Tichadou S, Hascoet J Y (2017). A knowledge-based intelligent decision system for production planning. International Journal of Advanced Manufacturing Technology, 89(5-8): 17171729

Ameri F, McArthur C (2013). A multi-agent system for autonomous supply chain configuration. International Journal of Advanced Manufacturing Technology, 66(5-8): 1097-1112

An D, Kim N H, Choi J H (2015). Practical options for selecting datadriven or physics-based prognostics algorithms with reviews. Reliability Engineering \& System Safety, 133: 223-236

Angles R, Gutierrez C (2008). Survey of graph database models. ACM Computing Surveys, 40(1): 1-39

Aouchiche M, Hansen P (2013). A survey of Nordhaus-Gaddum type relations. Discrete Applied Mathematics, 161(4-5): 466-546
Arshinder K, Kanda A, Deshmukh S G (2011). A review on supply chain coordination: Coordination mechanisms, managing uncertainty and research directions. In: Choi T-M, Cheng T C E, eds. Supply Chain Coordination under Uncertainty. Berlin: Springer

Bao J M, Hu T T, Pan L, Xu H, Hu H F (2014). Heterogeneous data integration and fusion system based on metadata conflict algorithms in USPIOT. In: Proceedings of 2014 International Conference on Wireless Communication and Sensor Network. 95-100

Baraldi P, Mangili F, Zio E (2012). A kalman filter-based ensemble approach with application to turbine creep prognostics. IEEE Transactions on Reliability, 61(4): 966-977

Batini C, Cappiello C, Francalanci C, Maurino A (2009). Methodologies for data quality assessment and improvement. ACM Computing Surveys, 41(3): 1-52

Bergman M, Milo T, Novgorodov S, Tan W C (2015). Query-oriented data cleaning with oracles. In: Proceedings of the 2015 ACM SIGMOD International Conference on Management of Data, New York, USA. 1199-1214

Bertsimas D, Griffith J D, Gupta V, Kochenderfer M J, Mišić V V (2017). A comparison of Monte Carlo tree search and rolling horizon optimization for large-scale dynamic resource allocation problems. European Journal of Operational Research, 263(2): 664-678

Bider I, Perjons E, Elias M, Johannesson P (2017). A fractal enterprise model and its application for business development. Software \& Systems Modeling, 16(3): 663-689

Bititci U S, Martinez V, Albores P, Parung J (2004). Creating and managing value in collaborative networks. International Journal of Physical Distribution \& Logistics Management, 34(3/4): 251-268

Brandes U, Borgatti S P, Freeman L C (2016). Maintaining the duality of closeness and betweenness centrality. Social Networks, 44: 153-159

Browning T R (2016). Design structure matrix extensions and innovations: A survey and new opportunities. IEEE Transactions on Engineering Management, 63(1): 27-52

Browning T R, Yassine A A (2016). Managing a portfolio of product development projects under resource constraints. Decision Sciences, 47(2): 333-372

Buldyrev S V, Parshani R, Paul G, Stanley H E, Havlin S (2010). Catastrophic cascade of failures in interdependent networks. Nature, 464(7291): 1025-1028

Byramjee F, Bhagat P, Klein A (2010). The Moderating Role of Relationship Quality in Determining Total Value Orientation. Rochester: Social Science Research Network

Caesarendra W, Widodo A, Thom P H, Yang B S, Setiawan J D (2011). Combined probability approach and indirect data-driven method for bearing degradation prognostics. IEEE Transactions on Reliability, 60(1): 14-20

Cai M, Zhang W Y, Zhang K (2011). ManuHub: A semantic web system for ontology-based service management in distributed manufacturing environments. IEEE Transactions on Systems, Man, and Cybernetics. Part A, Systems and Humans, 41(3): 574-582

Cao W, Jiang P (2013). Modelling on service capability maturity and resource configuration for public warehouse product service systems. International Journal of Production Research, 51(6): 1898-1921

Castillo E D (2006). Statistical process adjustment: A brief retrospective, current status, and some opportunities for further work. Statistica Neerlandica, 60(3): 309-326 
Chang Y C, Hsieh Y L, Chen C C, Hsu W L (2017). A semantic framebased intelligent agent for topic detection. Soft Computing, 21(2): 391-401

Chen D (2015). A methodology for developing service in virtual manufacturing environment. Annual Reviews in Control, 39: 102117

Chen T, Xu R, He Y, Wang X (2017). Improving sentiment analysis via sentence type classification using BiLSTM-CRF and CNN. Expert Systems with Applications, 72: 221-230

Chen T Y, Chen Y M, Wang T S (2015). Developing an ontology-based knowledge combination mechanism to customise complementary knowledge content. International Journal of Computer Integrated Manufacturing, 28(5): 501-519

Cheng C S, Cheng H P (2011). Using neural networks to detect the bivariate process variance shifts pattern. Computers \& Industrial Engineering, 60(2): 269-278

Cheng Y, Farooq S, Johansen J (2011). Manufacturing network evolution: A manufacturing plant perspective. International Journal of Operations \& Production Management, 31(12): 1311-1331

Ching W K, Choi S M, Huang X (2011). Inducing high service capacities in outsourcing via penalty and competition. International Journal of Production Research, 49(17): 5169-5182

Chinnam R B (2002). Support vector machines for recognizing shifts in correlated and other manufacturing processes. International Journal of Production Research, 40(17): 4449-4466

Chu X, Ilyas I F, Papotti P (2013). Discovering denial constraints. The Proceeding of the VLDB Endowment, 6(13): 1498-1509

Dai W, Maropoulos P G, Zhao Y (2015). Reliability modelling and verification of manufacturing processes based on process knowledge management. International Journal of Computer Integrated Manufacturing, 28(1): 98-111

Dalal S, Jaglan D V, Sharma D K K (2014). Designing architecture of demand forecasting tool using multi-agent system. International Journal of Advanced Research in Engineering and Applied Sciences, 3(1): 11-20

Ding J, Liu Y, Zhang L, Wang J (2014). MapReduce for large-scale monitor data analyses. In: Proceedings of IEEE International Conference on Trust. 747-754

Ding K, Jiang P, Su S (2018). RFID-enabled social manufacturing system for inter-enterprise monitoring and dispatching of integrated production and transportation tasks. Robotics and Computerintegrated Manufacturing, 49: 120-133

Doukas M, Psarommatis F, Mourtzis D (2014). Planning of manufacturing networks using an intelligent probabilistic approach for mass customised products. International Journal of Advanced Manufacturing Technology, 74(9-12): 1747-1758

Dries A, Rückert U (2009). Adaptive concept drift detection. Statistical Analysis and Data Mining: The ASA Data Science Journal, 2: 311327

Elwell R, Polikar R (2011). Incremental learning of concept drift in nonstationary environments. IEEE Transactions on Neural Networks, 22(10): 1517-1531

Eslami M H, Lakemond N (2016). Internal integration in complex collaborative product development projects. International Journal of Innovation Management, 20(01): 1650008

Fan J, Ghurye S G, Levine R A (2000). Multicomponent lifetime distributions in the presence of ageing. Journal of Applied Probability, 37(02): 521-533

Feldman K, Jazouli T, Sandborn P A (2009). A methodology for determining the return on investment associated with prognostics and health management. IEEE Transactions on Reliability, 58(2): 305316

Figueroa F, Schmalzel J (2006). Rocket testing and integrated system health management. In: Wang L H, Gao R X, eds. Condition Monitoring and Control for Intelligent Manufacturing, 373-391. London: Springer

Fink A, Kliewer N, Mattfeld D, Mönch L, Rothlauf F, Schryen G, Suhl L, Voß S (2014). Model-based decision support in manufacturing and service networks. Business \& Information Systems Engineering, 6 (1): $17-24$

Foreman J, Gallien J, Alspaugh J, Lopez F, Bhatnagar R, Teo C C, Dubois C (2010). Implementing supply-routing optimization in a make-to-order manufacturing network. M\&SOM, 12(4): 547-568

GóMez-Gasquet P, Lario F-C, Franco R-D, Anaya-Fons V (2011). A framework for improving planning-scheduling collaboration in industrial production environment. Studies in Informatics and Control, 20(20): 68

Gröger C, Schlaudraff J, Niedermann F, Mitschang B (2012). Warehousing manufacturing data. In: Kambayashi Y, Winiwarier W, Arikawa M, eds. Data Warehousing and Knowledge Discovery. Berlin: Springer

Gu J, Barker D, Pecht M (2007). Prognostics implementation of electronics under vibration loading. Microelectronics and Reliability, 47(12): 1849-1856

Guide V D R Jr, van Wassenhove L N (2009). OR FORUM-The evolution of closed-loop supply chain research. Operations Research, 57(1): 10-18

Guo C Q (2015). "Internet +": Disruptive innovation - an industrial, economic and social revolution. In: Proceedings of Forum on Collaborative Innovation and Development of Intelligent Manufacturing (in Chinese)

Guo H, Tao F, Zhang L, Laili Y J, Liu D K (2012). Research on measurement method of resource service composition flexibility in service-oriented manufacturing system. International Journal of Computer Integrated Manufacturing, 25(2): 113-135

Guo X, Sun S X, Vogel D (2014). A dataflow perspective for business process integration. ACM Transactions on Management Information Systems, 5(4): 1-33

Guo Z X, Ngai E W T, Yang C, Liang X (2015). An RFID-based intelligent decision support system architecture for production monitoring and scheduling in a distributed manufacturing environment. International Journal of Production Economics, 159: 16-28

Han L, Jiang P, Yu Y, Guo B (2014). Bayesian reliability evaluation for customized products with zero-failure data under small sample size. In: Proceedings of IEEE International Conference on Reliability. 904-907

Heckmann I, Comes T, Nickel S (2015). A critical review on supply chain risk - Definition, measure and modeling. Omega, 52: 119-132

Hegge H M H, Wortmann J C (1991). Generic bill-of-material: A new product model. International Journal of Production Economics, 23(13): $117-128$

Helo P, Suorsa M, Hao Y, Anussornnitisarn P (2014). Toward a cloud- 
based manufacturing execution system for distributed manufacturing. Computers in Industry, 65(4): 646-656

Hirshorn S R V (2017). NASA Systems Engineering Handbook. New York: Diane Publishing

Hong S, Lv C, Zhao T, Wang B, Wang J, Zhu J (2016). Cascading failure analysis and restoration strategy in an interdependent network. Journal of Physics A Mathematical and Theoretical, 49(19): 195101

Hornik K, Stinchcombe M, White H (1989). Multilayer feedforward networks are universal approximators. Neural Networks, 2(5): 359 366

Houshmand M, Valilai O F (2013). A layered and modular platform to enable distributed CAx collaboration and support product data integration based on STEP standard. International Journal of Computer Integrated Manufacturing, 26(8): 731-750

Jaw L C (2005). Recent Advancements in Aircraft Engine Health Management (EHM) Technologies and Recommendations for the Next Step. Reno: ASME

Jayaram J, Kannan V R, Tan K C (2004). Influence of initiators on supply chain value creation. International Journal of Production Research, 42(20): 4377-4399

Jia X, Nadarajah S, Guo B (2017). Bayes estimation of $\mathrm{P}(Y<X)$ for the Weibull distribution with arbitrary parameters. Applied Mathematical Modelling, 47: 249-259

Jiao H, Zhang J, Li J H, Shi J (2017). Research on cloud manufacturing service discovery based on latent semantic preference about OWL-S. International Journal of Computer Integrated Manufacturing, 30: 433-441

Jin Y, Ryan J K (2012). Price and service competition in an outsourced supply chain. Production and Operations Management, 21(2): 331344

Judd J (1987). Learning in networks is hard. In: Proceedings of IEEE International Conference on Neural Networks. 2: 685-692

Kacprzynski G J, Roemer M J, Hess A J (2002). Health management system design: Development, simulation and cost/benefit optimization. In: Proceedings of IEEE Aerospace Conference. 6: 3065-3072

Kadry S (2013). Diagnostics and Prognostics of Engineering Systems: Methods and Techniques. Pennsylvania: IGI Global

Kayış E, Erhun F, Plambeck E L (2012). Delegation vs. control of component procurement under asymmetric cost information and simple contracts. M\&SOM, 15(1): 45-56

Khalfallah M, Figay N, Silva C F D, Ghodous P (2016). A cloud-based platform to ensure interoperability in aerospace industry. Journal of Intelligent Manufacturing, 27(1): 119-129

Kim S H, Netessine S (2013). Collaborative cost reduction and component procurement under information asymmetry. Management Science, 59(1): 189-206

Kolahi S, Lakshmanan L V S (2009). On approximating optimum repairs for functional dependency violations. In: Proceedings of the 12th International Conference on Database Theory, New York, USA. 5362

La Rosa M, Dumas M, Uba R, Dijkman R (2013). Business process model merging: An approach to business process consolidation. ACM Transactions on Software Engineering and Methodology, 22 (2): $1-42$

Laalaoui Y, Bouguila N (2014). Pre-run-time scheduling in real-time systems: Current researches and artificial intelligence perspectives.
Expert Systems with Applications, 41(5): 2196-2210

Lee J, Kao H A, Yang S (2014). Service innovation and smart analytics for industry 4.0 and big data environment. Procedia CIRP, 16: 3-8

Lee S D, Park P (2015). The development of carrier aviation support system architecture using DoDAF. Journal of the Korea Society of Systems Engineering, 11(1): 33-39

Li J Q, Yu F R, Deng G, Luo C, Ming Z, Yan Q (2017). Industrial internet: A survey on the enabling technologies, applications, and challenges. IEEE Communications Surveys and Tutorials, 19(3): $1504-1526$

Li L, Qiao F (2012). A modular simulation system for semiconductor manufacturing scheduling. Przeglad Elektrotechniczny, 88: 12-18

Li P, Wang H, Zhu K Q, Wang Z, Hu X, Wu X (2015). A large probabilistic semantic network based approach to compute term similarity. IEEE Transactions on Knowledge and Data Engineering, 27(10): 2604-2617

Li Q, Luo H, Xie P X, Feng X Q, Du R Y (2015). Product whole lifecycle and omni-channels data convergence oriented enterprise networks integration in a sensing environment. Computers in Industry, 70: 23-45

Li W, Pham H (2005). Reliability modeling of multi-state degraded systems with multi-competing failures and random shocks. IEEE Transactions on Reliability, 54(2): 297-303

Liang L, Atkins D (2013). Designing service level agreements for inventory management. Production and Operations Management, 22: 1103-1117

Liang Z, Wang Y (2013). A web content recommendation method based on data provenance tracing and forecasting. In: Wong W E, Ma T, eds. Emerging Technologies for Information Systems, Computing, and Management. New York: Springer

Lim S C J, Liu Y, Lee W B (2011). A methodology for building a semantically annotated multi-faceted ontology for product family modelling. Advanced Engineering Informatics, 25(2): 147-161

Lin J T, Chiu C C (2018). A hybrid particle swarm optimization with local search for stochastic resource allocation problem. Journal of Intelligent Manufacturing, 29(3): 481-495

Lin T Y, Yang C, Zhuang C, Xiao Y, Tao F, Shi G, Geng C (2017). Multi-centric management and optimized allocation of manufacturing resource and capability in cloud manufacturing system. Journal of Engineering Manufacture, 231(12): 2159-2172

Lin W, Qian Y, Li X (2000). Nonlinear dynamic principal component analysis for on-line process monitoring and diagnosis. Computers \& Chemical Engineering, 24(2-7): 423-429

Lin Y H, Li Y F, Zio E (2015). Integrating random shocks into multistate physics models of degradation processes for component reliability assessment. IEEE Transactions on Reliability, 64(1): 154-166

Liu J, Chen M, Wang L, Wu Q (2014). A task-oriented modular and agent-based collaborative design mechanism for distributed product development. Chinese Journal of Mechanical Engineering, 27(3): 641-654

Liu S, Chen H, Guo B, Jia X, Qi J (2017). Residual life estimation by fusing few failure lifetime and degradation data from real-time updating. In: Proceedings of 2017 IEEE International Conference on Software Quality, Reliability and Security Companion (QRS-C). 177-184 
Liu W, Xie D, Xu X (2013). Quality supervision and coordination of logistic service supply chain under multi-period conditions. International Journal of Production Economics, 142(2): 353-361

Liu W H, Xie D (2013). Quality decision of the logistics service supply chain with service quality guarantee. International Journal of Production Research, 51(5): 1618-1634

Lu C J, Meeker W Q, Escobar L A (1996). A comparison of degradation and failure-time analysis methods for estimating a time-to-failure distribution. Statistica Sinica, 6: 531-546

Luca D (2015). Neural networks for parameters prediction of an electromagnetic forming process of $\mathrm{FeP} 04$ steel sheets. International Journal of Advanced Manufacturing Technology, 80(1-4): 689-697

Lusch R F, Vargo S L, Tanniru M (2010). Service, value networks and learning. Journal of the Academy of Marketing Science, 38(1): 19-31

Madni A M, Sievers M (2014). Systems integration: Key perspectives, experiences, and challenges. Systems Engineering, 17(1): 37-51

Maier A, Schriegel S, Niggemann O (2017). Industrial Internet of Things. Cham: Springer

Maltzahn S, Anderl R (2011). Early BOM Derivation from Requirement Specifications by Reusing Product Knowledge. In: Proceedings of ASME 2011 International Design Engineering Technical Conferences and Computers and Information in Engineering Conference, American Society of Mechanical Engineers. 1189-1195

Manupati V K, Kanigalpula P K C, Varela M L R, Putnik G D, Araújo A F, Vieira G G (2018). Developments and Advances in Intelligent Systems and Applications. Cham: Springer

Marsillac E, Roh J J (2014). Connecting product design, process and supply chain decisions to strengthen global supply chain capabilities. International Journal of Production Economics, 147: 317-329

Martinez-Hernandez V (2003). Understanding value creation: The value matrix and the value cube. Dissertation for the Doctoral Degree. Scotland: University of Strathclyde

McElheran K (2015). Do market leaders lead in business process innovation? The case(s) of E-business adoption. Management Science, 61(6): 1197-1216

Meeker W Q, Escobar L A, Lu C J (1998). Accelerated degradation tests: Modeling and analysis. Technometrics, 40(2): 89-99

Mendes J M, Leitão P, Colombo A W, Restivo F (2012). High-level Petri nets for the process description and control in service-oriented manufacturing systems. International Journal of Production Research, 50(6): 1650-1665

Millar R C (2007). A systems engineering approach to PHM for military aircraft propulsion systems. In: Proceedings of 2007 IEEE Aerospace Conference. 1-9

Modekurthy V P, Liu X F, Fletcher K K, Leu M C (2015). Design and implementation of a broker for cloud additive manufacturing services. Journal of Manufacturing Science and Engineering, 137 (4): 040904

Morris H, Lee S, Shan E, Zeng S (2004). Information integration framework for product life-cycle management of diverse data. Journal of Computing and Information Science in Engineering, 4(4): 352-358

Moura M C, Zio E, Lins I D, Droguett E, and the Moura M das C (2011). Failure and reliability prediction by support vector machines regression of time series data. Reliability Engineering \& System Safety, 96(11): 1527-1534
Müller M (2007). Dynamic Time Warping, Information Retrieval for Music and Motion. Berlin: Springer

Nasser S, Turcic D (2017). Temporary Price Discount to a Retailer with a Private Demand Forecast. Beijing: Social Science Electronic Publishing

Neches R, Madni A M (2013). Towards affordably adaptable and effective systems. Systems Engineering, 16(2): 224-234

Nguyen H, Dumas M, Hofstede A H M, Rosa M L, Maggi F M (2016). Advanced Information Systems Engineering. Cham: Springer

Nugraheni E, Akbar S, Saptawati G A P (2016). Framework of semantic data warehouse for heterogeneous and incomplete data. In: Proceedings of 2016 IEEE Region 10 Symposium (TENSYMP). 161-166

Oh S, Özer Ö (2012). Mechanism design for capacity planning under dynamic evolutions of asymmetric demand forecasts. Management Science, 59(4): 987-1007

Orchard M, Wu B, Vachtsevanos G (2005). A particle filtering framework for failure prognosis. Intelligent Control Systems Laboratory, 883-884

Papakostas N, Pintzos G, Giannoulis C, Chryssolouris G (2016). An agent-based collaborative platform for the design of assembly lines. International Journal of Computer Integrated Manufacturing, 29(4): 374-385

Parraguez P, Eppinger S, Maier A (2016). Characterizing design process interfaces as organization networks: Insights for engineering systems management. Systems Engineering, 19(2): 158-173

Paulheim H (2017). Knowledge graph refinement: A survey of approaches and evaluation methods. Semantic Web, 8(3): 489-508

Pecht M (2009). Prognostics and health management of electronics. Encyclopedia of Structural Health Monitoring, American Cancer Society

Pirani M, Bonci A, Longhi S (2016). A scalable production efficiency tool for the robotic cloud in the fractal factory. In: Proceedings of IECON 2016 - 42nd Annual Conference of the IEEE Industrial Electronics Society. 6847-6852

Priore P, Gómez A, Pino R, Rosillo R (2014). Dynamic scheduling of manufacturing systems using machine learning: An updated review. Artificial Intelligence for Engineering Design, Analysis and Manufacturing, 28(01): 83-97

Qian Y, Yan R (2015). Remaining useful life prediction of rolling bearings using an enhanced particle filter. IEEE Transactions on Instrumentation and Measurement, 64(10): 2696-2707

Qiu T, Luo D, Xia F, Deonauth N, Si W, Tolba A (2016). A greedy model with small world for improving the robustness of heterogeneous internet of things. Computer Networks, 101: 127-143

Qiu X, Lau H Y K (2014). An AIS-based hybrid algorithm for static job shop scheduling problem. Journal of Intelligent Manufacturing, 25 (3): 489-503

Quintanilla G F, Cardin O, L'Anton A, Castagna P (2016). A modeling framework for manufacturing services in Service-oriented Holonic Manufacturing Systems. Engineering Applications of Artificial Intelligence, 55: 26-36

Rahmani D, Heydari M (2014). Robust and stable flow shop scheduling with unexpected arrivals of new jobs and uncertain processing times. Journal of Manufacturing Systems, 33(1): 84-92

Reiner G (2005). Customer-oriented improvement and evaluation of supply chain processes supported by simulation models. International 
Journal of Production Economics, 96(3): 381-395

Roels G, Karmarkar U S, Carr S (2010). Contracting for collaborative services. Management Science, 56(5): 849-863

Romanowski C J, Nagi R (2005). On comparing bills of materials: a similarity/distance measure for unordered trees. IEEE Transactions on Systems, Man, and Cybernetics. Part A, Systems and Humans, 35 (2): 249-260

Sankararaman S, Mahadevan S (2015). Integration of model verification, validation, and calibration for uncertainty quantification in engineering systems. Reliability Engineering \& System Safety, 138: 194209

Saranga H, Moser R (2010). Performance evaluation of purchasing and supply management using value chain DEA approach. European Journal of Operational Research, 207(1): 197-205

Schouten K, Frasincar F (2016). Survey on aspect-level sentiment analysis. IEEE Transactions on Knowledge and Data Engineering, 28 (3): $813-830$

Senderovich A, Weidlich M, Yedidsion L, Gal A, Mandelbaum A, Kadish S, Bunnell C A (2016). Conformance checking and performance improvement in scheduled processes: A queueingnetwork perspective. Information Systems, 62: 185-206

Shen W, Han J, Wang J, Yuan X, Yang Z (2018). SHINE +: A general framework for domain-specific entity linking with heterogeneous information networks. IEEE Transactions on Knowledge and Data Engineering, 30(2): 353-366

Shin H J, Cho K W, Oh C H (2018). SVM-based dynamic reconfiguration cps for manufacturing system in industry 4.0. Wireless Communications and Mobile Computing, 2018: 1-13

Sicotte H, Langley A (2000). Integration mechanisms and R\&D project performance. Journal of Engineering and Technology Management, 17(1): $1-37$

Sohail A, Dominic P D D (2015). Business process improvement: A process warehouse based resource management method. In: Proceedings of International Symposium on Technology Management. 291-296

Song S, Chen L (2011). Differential dependencies: Reasoning and discovery. ACM Transactions on Database Systems, 36(3): 1-41

Stavrulaki E, Davis M M (2014). A typology for service supply chains and its implications for strategic decisions. Service Science, 6(1): 3446

Stuckenbruck L C (1997). Integration: The essential function of project management. In: Cleland D I, King W R, eds. Project Management Handbook. Hoboken: John Wiley \& Sons

Sun J, Debo L (2014). Sustaining long-term supply chain partnerships using price-only contracts. European Journal of Operational Research, 233(3): 557-565

Sun W, Shao S, Yan R (2016). Induction motor fault diagnosis based on deep neural network of sparse auto-encoder. Journal of Mechanical Engineering, 52(9): 65-71

Sun Y, Du Y, Li M (2017). A repair of workflow models based on mirroring matrices. International Journal of Parallel Programming, 45(4): 1001-1020

Tang X, Yun H (2008). Data model for quality in product lifecycle. Computers in Industry, 59(2-3): 167-179

Tanriverdi H, Konana P, Ge L (2007). The choice of sourcing mechanisms for business processes. Information Systems Research,
18(3): 280-299

Taratukhin V V, Yadgarova Y V (2016). Emerging Trends in Information Systems.Cham: Springer

Teran H, Hernandez J C, Vizán A, Ríos J (2014). Performance measurement integrated information framework in e-Manufacturing. Enterprise Information Systems, 8(6): 607-629

Thiraviam A, Mudge W, Malone L (2009). Six challenges in implementation of effective Accelerated Life Tests. In: Proceedings of 2009 Annual Reliability and Maintainability Symposium. 47-52

Tobon-Mejia D A, Medjaher K, Zerhouni N, Tripot G (2012). A datadriven failure prognostics method based on mixture of gaussians hidden markov models. IEEE Transactions on Reliability, 61(2): 491-503

Tsai C J, Huang H P (2007). A real-time scheduling and rescheduling system based on rfid for semiconductor foundry fabs. Journal of the Chinese Institute of Industrial Engineers, 24(6): 437-445

Tummala R, Schoenherr T (2011). Assessing and managing risks using the Supply Chain Risk Management Process (SCRMP). Supply Chain Management, 16(6): 474-483

Venkatesan D, Kannan K, Saravanan R (2009). A genetic algorithmbased artificial neural network model for the optimization of machining processes. Neural Computing \& Applications, 18(2): 135-140

Wang J M, Ren G Q, Zhang L, Liu Y B, Mo X N (2010). Maintenance repair and overhaul/operations support technology. Jisuanji Jicheng Zhizao Xitong, 16: 2017-2025(in Chinese)

Wang S, Du Y, Deng Y (2017). A new measure of identifying influential nodes: Efficiency centrality. Communications in Nonlinear Science and Numerical Simulation, 47: 151-163

Wang T Y, Chen L H (2002). Mean shifts detection and classification in multivariate process: A neural-fuzzy approach. Journal of Intelligent Manufacturing, 13(3): 211-221

Wang X, Balakrishnan N, Guo B (2014). Residual life estimation based on a generalized Wiener degradation process. Reliability Engineering \& System Safety, 124: 13-23

Wang X, Balakrishnan N, Guo B (2015). Residual life estimation based on nonlinear-multivariate Wiener processes. Journal of Statistical Computation and Simulation, 85(9): 1742-1764

Wang X, Balakrishnan N, Guo B, Jiang P (2015). Residual life estimation based on bivariate non-stationary gamma degradation process. Journal of Statistical Computation and Simulation, 85(2): 405-421

Wang Y G, Li Y J, Zheng B, Wang C (2008). Industrial value chain modeling based on industrial value matrix. In: Proceedings of 2008 Chinese Control and Decision Conference. 1100-1105

Wasmer A, Staub G, Vroom R W (2011). An industry approach to shared, cross-organisational engineering change handling - The road towards standards for product data processing. Computer Aided Design, 43(5): 533-545

Wei Y, Hu Q, Xu C (2013). Ordering, pricing and allocation in a service supply chain. International Journal of Production Economics, 144(2): 590-598

Whitaker J, Mithas S, Krishnan M S (2010). Organizational learning and capabilities for onshore and offshore business process outsourcing. Journal of Management Information Systems, 27(3): 11-42

Whyte J, Stasis A, Lindkvist C (2016). Managing change in the delivery 
of complex projects: Configuration management, asset information and 'big data'. International Journal of Project Management, 34(2): 339-351

Williams B D, Waller M A (2010). Creating order forecasts: point-ofsale or order history? Journal of Business Logistics, 31(2): 231-251

Winnig L W (2016). GE's big bet on data and analytics. MIT Sloan Management Review, 57

Wu S D, Wu P H, Wu C W, Ding J J, Wang C C (2012). Bearing fault diagnosis based on multiscale permutation entropy and support vector machine. Entropy (Basel, Switzerland), 14(8): 1343-1356

Wu X, Ryan S M (2011). Optimal replacement in the proportional hazards model with semi-markovian covariate process and continuous monitoring. IEEE Transactions on Reliability, 60(3): 580-589

Xie C, Cai H, Xu L, Jiang L, Bu F (2017). Linked semantic model for information resource service toward cloud manufacturing. IEEE Transactions on Industrial Informatics, 13(6): 3338-3349

Xiong J, Xing L, Chen Y (2013). Robust scheduling for multi-objective flexible job-shop problems with random machine breakdowns. International Journal of Production Economics, 141: 112-126

Xu D F, Li Q, Jun H-B, Browne J, Chen Y L, Kiritsis D (2009). Modelling for product information tracking and feedback via wireless technology in closed-loop supply chains. International Journal of Computer Integrated Manufacturing, 22: 648-670

Xu R, Zhai X (2010). Analysis of supply chain coordination under fuzzy demand in a two-stage supply chain. Applied Mathematical Modelling, 34(1): 129-139

Xu W, Yu J, Zhou Z, Xie Y, Pham D T, Ji C (2015). Dynamic modeling of manufacturing equipment capability using condition information in cloud manufacturing. Journal of Manufacturing Science and Engineering, 137(4): 040907

Xu X, Hua Q (2017). Industrial big data analysis in smart factory: Current status and research strategies. IEEE Access : Practical Innovations, Open Solutions, 5: 17543-17551

Yang X, Shi G, Zhang Z (2014). Collaboration of large equipment complete service under cloud manufacturing mode. International Journal of Production Research, 52(2): 326-336

Yang Y, Chen Y, Chen X, Liu X (2012). Multivariate industrial process monitoring based on the integration method of canonical variate analysis and independent component analysis. Chemometrics and Intelligent Laboratory Systems, 116: 94-101

Yang Y, Ren G (2017). Design of real time data acquisition system framework for production workshop based on OPC technology. MATEC Web of Conferences, 128: 02014

Yang Z, Zhang J, Wang S, Wang J, Huang X (2016). Building ontologybased bill of material design and knowledge management in power gird. In: 12th International Conference on Natural Computation, Fuzzy Systems and Knowledge Discovery (ICNC-FSKD), 16641669

Yazdi A S H, Kahani M (2014). A novel model for mining association rules from semantic web data. 2014 Iranian Conference on Intelligent Systems (ICIS), 1-4

Yeung W K, Choi T M, Cheng T C E (2011). Supply chain scheduling and coordination with dual delivery modes and inventory storage cost. International Journal of Production Economics, 132(2): 223229

Yousefi-Azar M, Hamey L (2017). Text summarization using unsuper- vised deep learning. Expert Systems with Applications, 68: 93-105

Yu Z, Wang H, Lin X, Wang M (2016). Understanding short texts through semantic enrichment and hashing. IEEE Transactions on Knowledge and Data Engineering, 28(2): 566-579

Yuan X, Hu Y, Stanley H E, Havlin S (2017). Eradicating catastrophic collapse in interdependent networks via reinforced nodes. Proceedings of the National Academy of Sciences of the United States of America, 114(13): 3311

Zampou E, Plitsos S, Karagiannaki A, Mourtos I (2014). Towards a framework for energy-aware information systems in manufacturing. Computers in Industry, 65(3): 419-433

Zhang C, Yao X, Zhang J (2015). Abnormal condition monitoring of workpieces based on rfid for wisdom manufacturing workshops. Sensors (Basel), 15(12): 30165-30186

Zhang D (2006). A network economic model for supply chain versus supply chain competition. Omega, 34(3): 283-295

Zhang F (2010). Procurement mechanism design in a two-echelon inventory system with price-sensitive demand. M\&SOM, 12(4): 608-626

Zhang F, Xue F, Xu F (2016). Collaborative modeling method of performance prototype for aerospace products based on ontology. Jisuanji Jicheng Zhizao Xitong, 22: 1887-1899 (in Chinese)

Zhang H, Diao Y, Immerman N (2010). Recognizing patterns in streams with imprecise timestamps. Proceedings of the VLDB Endowment International Conference on Very Large Data Bases, 3(1-2): 244-255

Zhang J, Jiang P, Guo B, Cheng Z (2017). The mixture of multi-kernel relevance vector machine with dynamic weights for real-time capacity estimation of lithium-ion batteries. In: Proceedings of 7th Asian-Pacific International Symposium on Advanced Reliability and Maintenance Modeling

Zhang J, Martin E B, Morris A J (1997). Process monitoring using nonlinear statistical techniques. Chemical Engineering Journal, 67(3): 181-189

Zhang O Q, Ko R K L, Kirchberg M, Suen C H, Jagadpramana P, Lee B $S$ (2012). How to track your data: Rule-based data provenance tracing algorithms. In: Proceedings of IEEE International Conference on Trust. 1429-1437

Zhang T, Gu X, He E (2014). Heterogeneous problems and elimination methods for modular ontology of product knowledge engineering. Lecture Notes in Electrical Engineering, 271: 43-50

Zhang W, Zhang S, Zhang S, Yu D (2016). A novel method for MCDM and evaluation of manufacturing services using collaborative filtering and IVIF theory. Journal of Algorithms \& Computational Technology, 10(1): 40-51

Zhang W, Zhou D, Liu L (2013). Contracts for changing times: Sourcing with raw material price volatility and information asymmetry. M\&SOM, 16(1): 133-148

Zhang W N, Ming Z Y, Zhang Y, Liu T, Chua T S (2016). Capturing the semantics of key phrases using multiple languages for question retrieval. IEEE Transactions on Knowledge and Data Engineering, 28 (4): 888-900

Zhang W Y, Zhang S, Chen Y G, Pan X W (2013). Combining social network and collaborative filtering for personalised manufacturing service recommendation. International Journal of Production Research, 51(22): 6702-6719

Zhang Y, Guo B (2015). Online capacity estimation of lithium-ion 
batteries based on novel feature extraction and adaptive multi-kernel relevance vector machine. Energies, 8(11): 12439-12457

Zhang Y, Ren Z J (2011). Service outsourcing. In: Cochran J J, eds. Wiley Encyclopedia of Operations Research and Management Science. New York: Wiley

Zhao F, Tian Z, Bechhoefer E, Zeng Y (2015). An integrated prognostics method under time-varying operating conditions. IEEE Transactions on Reliability, 64(2): 673-686

Zhao F, Tian Z, Zeng Y (2013). Uncertainty quantification in gear remaining useful life prediction through an integrated prognostics method. IEEE Transactions on Reliability, 62(1): 146-159

Zheng W, Hsu H, Zhong M, Yun M (2015). Requirements analysis for future satellite gravity mission improved-GRACE. Surveys in Geophysics, 36(1): 87-109

Zhou S, Wang P (2009). The integration of multi-source heterogeneous data based on middleware. In: Proceedings of 1st International Conference on Information Science and Engineering. 2213-2216
Zhou Y, Chen J, Dong G M, Xiao W B, Wang Z Y (2012). Application of the horizontal slice of cyclic bispectrum in rolling element bearings diagnosis. Mechanical Systems and Signal Processing, 26: 229-243

Zhu S P, Huang H Z, Peng W, Wang H K, Mahadevan S (2016). Probabilistic physics of failure-based framework for fatigue life prediction of aircraft gas turbine discs under uncertainty. Reliability Engineering \& System Safety, 146: 1-12

Zhu X, Song S, Lian X, Wang J, Zou L (2014). Matching heterogeneous event data. In: Proceedings of the 2014 ACM SIGMOD International Conference on Management of Data, New York, USA. 1211-1222

Zio E, Di Maio F (2012). Fatigue crack growth estimation by relevance vector machine. Expert Systems with Applications, 39(12): 1068110692

Žliobaitė I, Bifet A, Pfahringer B, Holmes G (2011). Active learning with evolving streaming data. In: Machine Learning and Knowledge Discovery in Databases. Berlin: Springer 